\title{
LEI DO ABORTO EM PORTUGAL Barreiras atuais e desafios futuros
}

Miguel Areosa Feio

Instituto Superior de Psicologia Aplicada / Iscte - Instituto Universitário de Lisboa, Lisboa, Portugal

Resumo A despenalização do aborto previu eliminar os abortos clandestinos, embora ainda existam barreiras ao aborto seguro que afetam mais as mulheres desfavorecidas: objeção de consciência, prazos demasiado curtos para o procedimento, períodos de reflexão obrigatórios ou a estigmatização. Foi investigada a relação entre a formulação legislativa e a sua implementação, sendo que eventuais discrepâncias atestam a falência parcial dos seus objetivos. Foram analisados os dados quantitativos da DGS e qualitativos provenientes de entrevistas e focus group com especialistas e profissionais de saúde. As evidências produziram orientações para debates futuros.

Palavras-chave: aborto, objeção de consciência, teoria dos fluxos múltiplos, aborto clandestino

\section{Abortion law in Portugal: current barriers and upcoming challenges}

Abstract The decriminalization of abortion aimed to end clandestine abortions, but are still some barriers to safe abortion that affect, mostly, women in disadvantaged situations: conscientious objection, too short procedure deadlines, mandatory reflection periods or stigmatization. The links between the legislative formulation and its implementation was investigated and any eventual discrepancies attest the partial failure of its objectives. DGS quantitative data and qualitative information from interviews and focus group with specialists and health professionals, were analysed. The evidence provided clues to future debate.

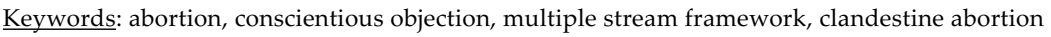

\section{Loi sur l'avortement au Portugal: obstacles actuels et défis futurs}

Résumé La dépénalisation de l'avortement visait à mettre fin aux avortements clandestins. Cependant, des obstacles qui affectent plus les femmes défavorisées restent à l'évidence: l'objection de conscience, des délais de procédure trop courts, des périodes de réflexion obligatoires ou la stigmatisation. La recherche sur la relation entre la formulation législative et sa mise, basée sur des données quantitatives de la DGS et qualitatives d'entretiens et de groupes de discussion avec des spécialistes et des professionnels de la santé, témoigne de l'échec partiel de ses objectifs. Cette évidence fournie, par ailleurs, des éléments pour un débat futur.

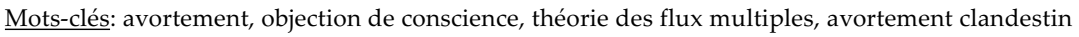

\section{Ley del aborto en Portugal: obstáculos actuales y retos futuros}

Resumen La despenalización del aborto preveía eliminar los abortos clandestinos, aunque todavía subsistan, hoy en día, barreras a la práctica de un aborto seguro, que afectan más a las mujeres desfavorecidas: la objeción de conciencia, plazos demasiado cortos para llevar a cabo el procedimiento, períodos obligatorios de reflexión o incluso el estigma que recae sobre la propia persona. En este trabajo se investigó la relación entre la producción legislativa y su implementación. Las discrepancias que se verifican atestan que parte de sus objetivos han fallado. Se analizaron los datos cuantitativos de la DGS y datos cualitativos con origen en entrevistas y focus group con expertos y profesionales de salud. Las evidencias de este trabajo han producido orientaciones para debates futuros.

Palabras-clave: aborto, objeción de consciencia, aborto clandestino, multiple streams model 


\section{Introdução}

A lei n.o 16/2007, de 17 de abril, que despenaliza o aborto por opção da mulher e operacionaliza a sua implementação, completou 14 anos. Reflete-se agora acerca de uma lei que veio responder a dois problemas fundamentais: mortes e morbilidade de mulheres, e sua criminalização, ambos decorrentes de abortos clandestinos. Existem condições institucionais, pelo menos no plano formal, para que todas as mulheres que optem por interromper uma gravidez até às dez semanas o possam fazer em segurança. No entanto, parecem resistir na formulação e implementação legislativa marcas de estigma que podem comprometer, no plano material, a garantia plena desses direitos. A problemática deste artigo aborda a influência de atitudes estigmatizantes da parte de profissionais de saúde, manifestas pela objeção de consciência, e seu impacto no funcionamento dos serviços em diferentes zonas do território nacional. Adicionalmente, interessa perceber em que medida essa decisão pessoal, quando intersecionada com mecanismos da própria formulação legislativa, como o tempo de gestação até ao qual se pode realizar o procedimento, ou a obrigatoriedade de um período de reflexão, pode conduzir à opção por abortos inseguros. A ocorrência de abortos clandestinos nos dias de hoje é a hipótese a investigar, por via dos dados relativos à implementação da lei, sua eficácia e abrangência territorial, enfatizando eventuais constrangimentos. A reflexão proposta é realizada através de dados disponíveis nos organismos oficiais, bem como através da análise de informação retirada de testemunhos de pessoas de referência no trabalho de terreno e serviços de saúde.

\section{A evolução legal do aborto em Portugal e no mundo}

Os cuidados a prestar em saúde sexual e reprodutiva (SSR) abrangem serviços, técnicas e métodos que contribuem para a saúde e o bem-estar reprodutivos de mulheres e homens ao longo do seu ciclo de vida. O acesso à interrupção de gravidez (IG ou aborto) segura é uma questão de saúde reprodutiva, podendo o ato em si definir-se como a terminação de uma gravidez antes das 20 semanas ou antes da viabilidade fetal, um fenómeno decorrente da própria gestação (o caso dos abortos espontâneos), induzido por profissionais de saúde (quando tal é permitido), ou por outros motivos, no caso dos abortos provocados. ${ }^{1}$ (Cunningham et al., 2014; IPPF, 2008; U.S. National Library of Medicine - MedlinePlus, 2018).

Desde o final do século XX e início do século XXI, assistiu-se, um pouco por todo o mundo, a uma tendência para a liberalização do aborto ((Boland, Katzive e Boland, 2008), com contributos dos movimentos de defesa dos direitos das mulheres (Berer, 2004; Boland, Katzive e Boland, 2008; Finer e Fine, 2013) e da Organização Mundial de Saúde (OMS), que considerou, em 1967, o aborto clandestino como

1 A literatura anglo-saxónica distingue os conceitos de aborto espontâneo, com o termo miscarriage, do de aborto provocado, ou abortion. 
um sério problema de saúde pública (Berer, 2004; Finer e Fine, 2013). No entanto, entre $39 \%$ e $41 \%$ das mulheres de todo o mundo vivem em países com legislação restritiva face à interrupção da gravidez (Center for Reproductive Rights, 2019; Finer e Fine, 2013), sobretudo na Ásia, África e América Latina (Boland, Katzive e Boland, 2008; IPPF, 2012), e tem aumentado a percentagem de países que criminaliza a prática, o que parece indicar uma reversão da tendência verificada no início do século.

Em Portugal, o debate bebeu das experiências e práticas externas, apesar de o seu enquadramento legal ter estado sempre inscrito no âmbito do Código Penal, ou seja, tratado em termos das implicações criminais para as mulheres que o praticam (Finer e Fine, 2013; Levels, Sluiter e Need, 2014). As primeiras revindicações em relação ao aborto livre surgem após 1974 no sentido da sua despenalização, altura em que ocorreriam entre 100.000 e 200.000 abortos clandestinos por ano, dos quais $2 \%$ terminavam em morte (Tavares, 2008). No plano político, no início dos anos 80 , a ação dos organismos responsáveis pelos direitos da mulher, nomeadamente a ação da Comissão para a Cidadania e Igualdade de Género - à data Comissão da Condição Feminina - era condicionada pela convergência de um moralismo católico com o conservadorismo do governo da Aliança Democrática (PPD/PSD-CDS/PP-PPM) (Monteiro, 2012), pelo que, nessa altura os efeitos dos movimentos feministas não produziram mudanças tangíveis. Foi apenas em 1984 que, na conjuntura social descrita, mas com um governo do Partido Socialista e um parlamento com maioria de deputados de esquerda, se aprova a exclusão de ilicitude nos casos de perigo de vida física e psíquica da mulher, violação e malformação do feto, naquela que ficou conhecida como a Lei n.․ㅡ/84, de 11 de maio (exclusão de ilicitude em alguns casos de interrupção voluntária de gravidez, 1984).

Segundo a International Planned Parenthood Federation (IPPF), em 1984 existiam já vários países com legislação específica em torno da interrupção voluntária da gravidez (IVG), alguns dos quais a premitiam por opção da mulher até às 12 ou 13 semanas - a Finlândia (desde 1970), a Dinamarca (desde 1973), a Áustria (desde 1974), a França, a Noruega e a Suécia (desde 1975) e a Holanda (desde 1981) (IPPF, 2012). Países como Islândia (1975), Grécia (1978) e Itália (1978) instituíram legislação que permitia o aborto em situações excecionais mas não por opção da mulher, uma corrente que influenciou a formulação da lei portuguesa de 1984 e da lei espanhola de 1985. A redação legal portuguesa continha, aliás, formulações sem correspondência na sua implementação, já que a objeção de consciência e consequente inexistência de serviços clínicos - públicos e privados - para a IG, fazia com que grande parte das situações permitidas por lei, não fosse na prática realizada, perpetuando as práticas de aborto clandestino (Ana Campos [entrevista concedida a Miguel Areosa Feio a 22 de novembro de 2018]). ${ }^{2}$

2 Foram efetuadas duas entrevistas preliminares com pessoas consideradas como referências no tema. Foram elas o Dr. Francisco George, médico, professor e diretor-geral da Saúde entre 2005e 2017, e a Dr. ․ Ana Campos, médica, diretora clínica de obstetrícia da maternidade Alfredo da Costa e uma das pessoas que participaram no grupo de trabalho responsável pela elaboração dos procedimentos de implementação da lei. 
Se até ao início dos anos 90 a crescente mobilização dos grupos de interesse tinha tido um impacto marginal na promoção de políticas liberais face ao aborto (Yishai, 1993), o Programa de Ação da Conferência Internacional sobre Populaçãoe Desenvolvimento (ICPD), realizada no Cairo em 1994, levou a que 25 países promovessem mudanças legislativas de sentido liberalizante, decorrentes do compromisso com as resoluções do documento (Finer e Fine, 2013; Nações Unidas, 1994), e muitos movimentos sociais e ONG se mobilizassem para influenciar resoluções favoráveis ao direito ao aborto, como parte integrante do direito à SSR. Em Portugal, essa corrente manifestou-se pela mobilização de plataformas ligadas aos movimentos pró-escolha e da opinião pública que foi dando conta dos impactos dramáticos do aborto clandestino (Monteiro, 2012). Tal mobilização pressionou o agendamento político da despenalização do aborto, num fenómeno que se inseriu nos chamados movimentos sociais em saúde, desafiadores transversais dos sistemas de crenças instituídas, (Brown e Zavestoski, 2004). Em 1998, por acordo entre os líderes do PSD (na oposição) e PS (então governo), realiza-se o primeiro referendo à população, no qual o "Não" à despenalização por opção da mulher vence, resultado que poderá explicar-se pela maior organização da parte dos movimentos conservadores portugueses em torno da campanha, pela falta de envolvimento da parte do Partido Socialista (Alves et al., 2009) e devido à força da Igreja Católica, que apoiou, marcadamente e em várias frentes, o movimento antiescolha (Freire, 2008, cit. por Monteiro, 2012). Em 1999, 15 anos após a primeira lei de despenalização do aborto, apenas $1 \%$ a 2\% dos abortos se realizavam ao abrigo da legislação e em 2005 tinham sido realizados cerca de 17 mil abortos clandestinos em Portugal, numa clara disjunção entre a formulação e a implementação da lei (Monteiro, 2012). Para além disso, na década de 2000, os episódios de julgamento de mulheres pela prática de aborto constituíram acontecimentos decisivos na expansão de uma certa intolerância social à legislação restritiva (Alves et al., 2009).

\section{A lei n.. 16/2007: a confluência que conduziu à mudança}

O período de 2006-2007 constituiu um marco no debate e culmina com a aprovação da lei n.. 16/2007 que ainda hoje vigora. A mudança verificada foi o resultado de fatores contextuais e oportunidades políticas, que se desenvolveram sobre reivindicações antigas de movimentos de mulheres (Monteiro, 2012). Do ponto de vista da análise de políticas públicas o caminho que conduziu à despenalização do aborto até às dez semanas pode ser explicado à luz da teoria dos fluxos múltiplos de John Kingdom. O autor (Kingdom, 1984, cit. por Hill, 2009) defende que as políticas não surgem de forma automática para a resolução de problemas, mas sim de um processo dinâmico de interação entre vários intervenientes, que se operacionaliza pela conjugação de três fluxos no sistema político: o fluxo dos problemas, o fluxo das políticas (no sentido da policy) e o fluxo da política (a politics).

Neste processo de convergência a ação de "empreendedores" (o voluntarismo político) é um aspeto essencial no aproveitamento das janelas de oportunidade (Zahariadis, 2007). Devido ao facto de os decisores políticos se debaterem com 
constrangimentos temporais, o timing em que os fluxos convergem é fundamental no processo de surgimento da medida de política, sendo precisamente nesse tempo que a janela de oportunidade se concretiza, aspeto que pode ajudar a perceber as condições que conduziram à vitória do "Não" em 1998. No início do novo milénio, diversos atores-chave, sociais e políticos, fizeram emergir no debate das ideias argumentos associados aos direitos e autodeterminação das mulheres, reforçados pela influência de importantes recomendações das Nações Unidas e da OMS. Em simultâneo, observou-se uma maior convergência das políticas europeias em torno da IVG, às quais Portugal, enquanto país membro da União Europeia, não poderia ficar indiferente: por exemplo, países como Bélgica (1990) ou Alemanha (1995) formulam as suas leis de despenalização do aborto, incluindo por opção da mulher (IPPF, 2012). Aliás, o fenómeno de policy transfer, processo de apropriação de políticas de uns países por outros, ajuda a explicar a forma como os decisores políticos olharam em redor, no processo de agendamento e formulação política ou legislativa (Hill, 2009). Esta "sopa de ideias" (Zahariadis, 2007) potenciou o timing ideal para ação dos empreendedores, aos quais se juntou uma paralela e crescente atenção da opinião pública e da comunicação social para o tema, tornando a questão do aborto incontornável, enquanto demanda, para os decisores políticos (Howlett, 2000).

É neste contexto que o aborto se constitui como um problema político, sendo o seu reagendamento impulsionado pela opinião pública, sociedade civil organizada e media. Para que uma questão se constitua um problema é necessário que sejam verificáveis uma série de indicadores e eventos, e exista uma resposta social em relação a ele. No caso do aborto, tanto o número de procedimentos clandestinos cerca de 17 mil abortos clandestinos (no ano de 2005), que por vezes conduziam a mortes - como a criminalização de mulheres, de que é exemplo o mediático julgamento de 17 mulheres na Maia (e a consciência de que isso constituía uma dupla vitimização das mesmas), foram contributos para a elevação do aborto a problema político. O fluxo dos problemas, enquanto processo que faz com que uma dada questão seja merecedora de atenção política, está sempre dependente de questões interpretativas de comparações temporais ou geográficas (Kingdom, 1995, cit. por Zahariadis, 2007), pelo que a ação dos empreendedores políticos é especialmente relevante, pois parte deles, também, o trabalho de chamar a atenção para os referidos indicadores e mediatizar os fenómenos.

O fluxo da política manifestou-se no reagendamento do tema, concretizado pela inclusão de um novo referendo ao aborto no programa de governo do PS em 2005 (Programa do XVII Governo Constitucional, 2005), para o qual contribuíram, como vimos, uma forte componente mediática, de partilha de ideias e sentimentos comuns face ao tema, bem como a conjuntura nacional e internacional, nomeadamente a referida convergência de políticas ao nível da União Europeia. Segundo Kingdom (1995, cit., por Zahariadis, 2007) o fluxo da política depende da disposição nacional para o tema, da pressão de ativistas e de mudanças administrativas e no tema do aborto; constata-se que uma forte mobilização de movimentos feministas em contexto de governos de esquerda é receita para o seu agendamento (Blofield, 2008). Neste domínio, sublinha-se que o facto de um referendo estar incluído 


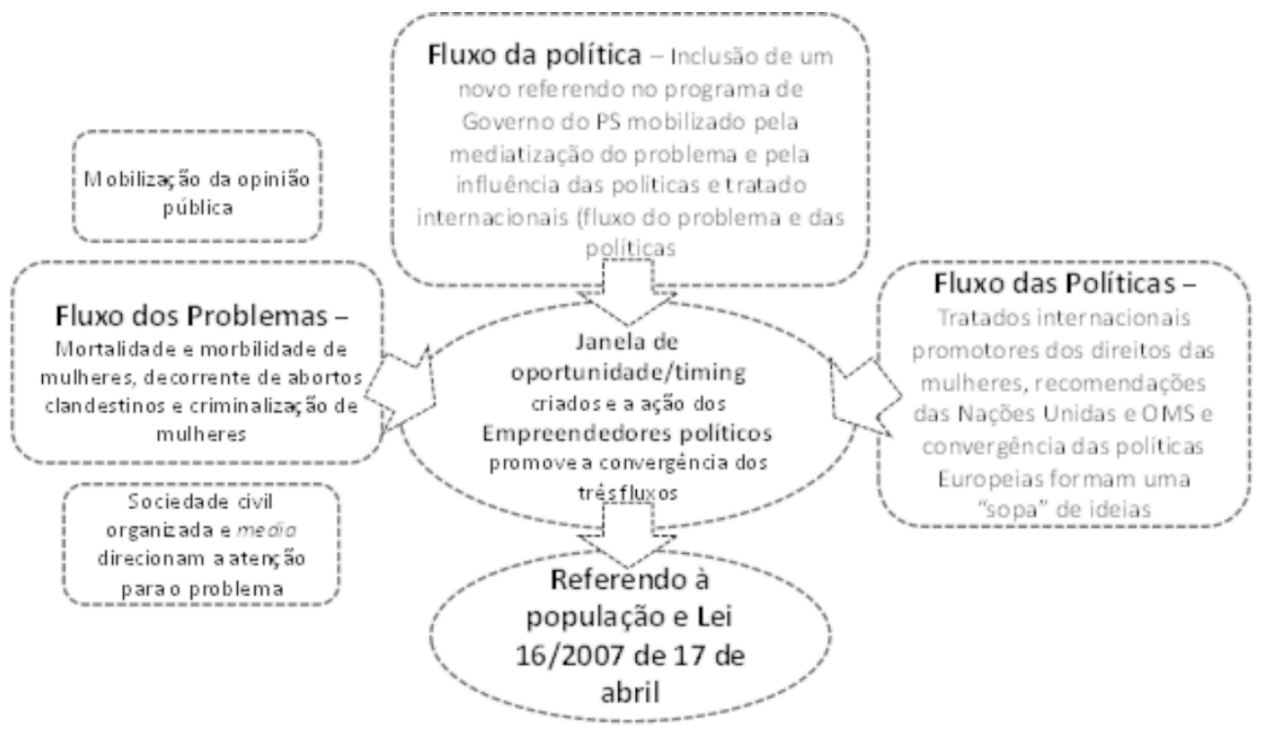

Figura 1 Processo de convergência dos três fluxos do Modelo de Kingdom (1984) que conduziu à mudança legislativa em relação à interrupção voluntária da gravidez em Portugal

no programa eleitoral do PS e a melhor organização estratégica da parte dos grupos de apoio ao movimento pró-escolha (em particular através do apoio da parte do grupo Médicos pela Escolha) contribuíram determinantemente para a mudança de paradigma (Ana Campos [entrevista concedida a Miguel Areosa Feio a 22 de novembro de 2018]). Em suma, o referendo à população de 11 de fevereiro de 2007 culmina com a despenalização da IVG, que se veio a traduzir na lei n. ${ }^{\circ}$ 16/2007, de 17 de abril, que vigora atualmente. O diagrama na figura 1 resume esquematicamente os processos acima descritos.

O aborto deixou de ser punível criminalmente, nas situações já previstas na legislação anterior e, adicionalmente, até às dez semanas de gestação por vontade expressa da mulher. De acordo com os dados disponibilizados pela Direção-Geral de Saúde até 2014 (DGS, 2011, 2013, 2015) nenhuma mulher morreu por complicações decorrentes de aborto ou foi condenada pela sua prática, após a mudança de 2007 (Alves et al., 2009). Existem, contudo, desafios a superar e é essa análise que se fará doravante.

\section{Barreiras no acesso ao aborto seguro}

Se até este ponto se abordaram os preceitos do agendamento e formulação legislativa, a partir daqui a análise incidirá sobre a sua implementação, aspeto para o qual se pretende investigar eventuais constrangimentos. A implementação da lei n.o 
16/2007 foi feita através das orientações técnicas formuladas pela DGS, imediatamente a seguir ao referendo (Stifani, Vilar e Vicente, 2018) e teve em conta a declaração de objeção de consciência que os profissionais de saúde poderiam fazer, após a qual ficavam inibidos de participar em qualquer dos passos do processo. Este procedimento permite determinar que serviços de saúde dispõem, ou não, de profissionais habilitados para a prática da IG.

Em Portugal o direito de objeção de consciência está previsto na Constituição da República Portuguesa (1976), deriva da ratificação, em 1978, do Pacto Internacional sobre os Direitos Civis e Políticos das Nações Unidas ${ }^{3}$ (1976) e, no que diz respeito aos profissionais de saúde, descreve-se nos códigos deontológicos das profissões médicas e de enfermagem (Código Deontológico, 2009; Regulamento Deontologia Médica, 2016). Historicamente, a objeção de consciência surge associada a atos pacifistas ou à tentativa de garantir uma excelência na prática profissional (Schuklenk, 2018), posição que pode encontrar correspondência no Código Deontológico da profissão médica em Portugal, que obriga a assistência em IG apenas nas situações que visem salvaguardar a vida da mulher grávida (sendo omisso em relação a todas as outras), reforçando que o objeto da profissão é o da "preservação da vida humana desde o seu início". Vários países tentam conciliar o direito à objeção de consciência com a garantia de que as mulheres acedem a cuidados de saúde legais e seguros (Chavkin, Leitman e Polin, 2013; Chavkin, Swerdlow e Fifield, 2017; Ortiz, 2017; Wicclair, 2011), seguindo, por exemplo, as recomendações da OMS (Doran e Nancarrow, 2015; Harris et al., 2018), que postula que o direito à objeção de consciência merece ser preservado apenas se garantir a plenitude no acesso à saúde, ou da Convenção para a Eliminação de Todas as Formas de Discriminação contra as Mulheres (Nações Unidas, 1979), que reconhece o direito de todas as mulheres em aceder a serviços de saúde reprodutiva ao mesmo tempo que defende o direito individual de religião, consciência e pensamento, e sugere que o acesso a cuidados de saúde não deve ser constrangido pelo direito à objeção de consciência (Chavkin, Leitman e Polin, 2013).

A acomodação do direito à objeção de consciência com a garantia de acesso a serviços de saúde parece ser um equilíbrio difícil de garantir. Se, por um lado, historicamente, essa acomodação tende a garantir ao profissional o espaço para a ética individual dentro da profissão médica (Schuklenk, 2018), acontece que alguns autores associam essa posição individual a uma verdadeira "desonrada desobediência", na medida em que a sua ocorrência, em cuidados de saúde reprodutiva e mesmo que de forma limitada, constrange os direitos da paciente à vida e à segurança (Fiala e Arthur, 2014, 2017). Para os autores a recusa de um procedimento com base na crença subjetiva do profissional é imoral, sendo irrelevante se é sincera ou não, extrema ou moderada, sendo sempre prejudicial.

Aquilo que se verifica é que, quando a objeção de consciência se intersecta com outras barreiras, pode constituir um problema acrescido sempre que existe

3 Artigo 18. ํㅡ - Toda a pessoa tem direito à liberdade de pensamento, de consciência e de religião; este direito inclui a liberdade de ter ou de adotar a religião ou as crenças de sua escolha, assim como a liberdade de manifestar a sua religião ou as suas crenças [...]. 
necessidade de encaminhamento para zonas geográficas distantes com custos associados (Harris et al., 2018), ou quando associado a fenómenos de estigmatização social (Autorino, Mattioli e Mencarini, 2020). Para além disso, o menor acesso a serviços de saúde impacta desproporcionadamente as mulheres cujas condições de vida são mais precárias, o que pode agravar desigualdades (Autorino, Mattioli e Mencarini, 2020; Chavkin, Leitman e Polin, 2013; Rasch et al., 2008).

$O$ fator género pode constituir per se uma forma de desigualdade social, na medida que tende a reproduzir padrões de exclusão sempre que, nas sociedades, existem diferenças entre mulheres e homens no que diz respeito às responsabilidades atribuídas, atividades realizadas, acesso e controle de recursos, bem como oportunidades de tomada de decisão (EIGE, 2017). A desigualdade de género é, grosso modo e dependendo das características sociais, culturais ou económicas, qualquer situação em que uma mulher se encontra em desvantagem em relação aos homens (Rinehart e Lorber, 2002) e, quando intersetada com outras, perpetua-se e dificilmente se esbate, constituindo verdadeiros sistemas de desigualdades (Costa, 2012). Ao nível das nações o acesso a cuidados de saúde é um bom indicador das desigualdades existentes (Wilkinson e Pickett, 2010), sendo nesses casos, invariavelmente, as mulheres quem tem menor acesso à saúde e quem, em termos de SSR, se encontra mais vulnerável: risco acrescido de contrariar VIH, mortalidade materna, gravidez adolescente, aborto ou violência de género (Rinehart e Lorber, 2002). Em países em que as desigualdades de género são mais facilmente repercutidas e em que os papéis das mulheres tendem a ser de estatuto inferior ao dos homens, assistimos a desigualdades ao nível do acesso a recursos educativos, financeiros e de saúde o que perpetua ciclos de exclusão (IPPF, 2017; Namasivayam et al., 2012).

O acesso equitativo a serviços de saúde, em particular a serviços de SSR, nos quais se inclui o acesso ao aborto seguro, contribui para esbater a interseção de desigualdades. A distribuição abrangente territorialmente, de serviços de aborto seguro é relevante para essa equidade no acesso e a sua ausência tende a discriminar aquelas mulheres com menores recursos de mobilidade ou acesso a informação. Segundo a DGS (2018) o perfil dominante das mulheres que recorre a IG caracteriza-se pela exclusão pessoal e social, associada a desemprego ou precariedade laboral, e a regimes de não coabitação, o que lhes coloca entraves em termos de autonomia e flexibilidade geográfica e financeira. Segundo um estudo dinamarquês (Rasch et al., 2008) a decisão de levar a cabo um aborto é mais frequente em mulheres de estratos socioeconómicos mais baixos e com precária relação com $\mathrm{o}$ mercado de trabalho, bem como entre mulheres imigrantes.

Para além da limitada abrangência geográfica, existem barreiras adicionais no acesso ao aborto seguro, das quais se destacam a idade gestacional até à qual é permitida a IG (dez semanas em Portugal), as restrições ao aborto medicamentoso, a obrigatoriedade de realização do procedimento em hospitais, a necessidade de validação do procedimento por dois profissionais, os períodos de espera obrigatórios, a autorização de partes terceiras (familiares, companheiros ou outros profissionais), ou ainda o acompanhamento psicossocial obrigatório (Finer e Fine, 2013; Culwell e Hurwitz, 2013; Levels, Sluiter e Need, 2014). Em Portugal, para além da necessidade de validação da idade gestacional por dois profissionais, existe um 
período de espera obrigatório de três dias e a disponibilização, não obrigatória, de acompanhamento psicossocial, procedimentos que podem remeter para estigmatização e preconceito. São barreiras transversais que influenciam comportamentos e representações fazendo com que profissionais de saúde atuem, muitas vezes, com uma predisposição moralizadora sobre as mulheres, promovendo dificuldades acrescidas no acesso ao aborto (Kaposy, 2010; Riedel e Hanschmidt, 2016). Ana Campos (Ana Campos [entrevista concedida a Miguel Areosa Feio a 22 de novembro de 2018]) indica que existem profissionais que manifestam objeção de consciência apenas em relação ao aborto por opção da mulher, estando disponíveis para o realizar noutras situações, não privilegiando a autonomia moral das mulheres e estigmatizando-as (Fiala e Arthur, 2014, 2017; Savulescu, 2006).

O estigma é a perceção que um individuo tem em relação ao menor valor, desonestidade, sistema de crenças ou comportamentos de outro (Goffman, 1963) e, por isso mesmo, é um aspeto nuclear no condicionamento da ação em relação ao aborto, na medida em que identifica elementos discriminatórios em quem o pratica ou a ele recorre. Aquele que é estigmatizado - nos três modos que define: seja por motivos de deficiência ou doença, por motivos de raça, religião ou nação, seja por comportamento ou caráter - carrega, recorrentemente, sentimentos de vergonha e culpa, sendo a discriminação, o afastamento ou a atribuição de menor estatuto a ação sistemática de quem estigmatiza (Goffman, 1963; Hatzenbuehler, Phelan e Link, 2013). O impacto do estigma na iniquidade no acesso ou qualidade na prestação de um serviço de saúde encontra-se amplamente descrito, nomeadamente no que diz respeito ao VIH, tuberculose, obesidade, deficiência ou doença mental, por exemplo, acontecendo, predominantemente se as pessoas tiverem, associadas à sua condição, outras características que as desfavoreçam, tais como o estatuto social, o conhecimento, o poder ou o dinheiro (Hatzenbuehler, Phelan e Link, 2013), características encontradas em casos de aborto, pelo menos em Portugal. Para estes autores, o estigma associado à saúde, tende a produzir isolamento, stress, ou outras reações psicológicas desajustadas, sendo um preditor importante da perpetuação da desigualdade no acesso à saúde, em particular da parte dos grupos já desfavorecidos. No caso do aborto, mulheres que percecionam estigma social ou da parte de profissionais descrevem sentir problemas de saúde mental, ponderam recorrer a abortos inseguros ou a realizar o seu procedimento em estados gestacionais mais tardios (Cartwright et al., 2018; Doran e Hornibrook, 2016; Jerman et al., 2017; Kero et al., 2001). A generalidade das mulheres que recorre ao aborto experimenta estigma percebido e real de fontes diversas: sociedade, comunidade religiosa, pessoas que lhes são próximas (familiares, amigos e companheiros) e até da parte dos serviços e profissionais de saúde (De Zordo, 2016; Riedel e Hanschmidt, 2016). Em países em que a legislação é mais moralizadora e restritiva ou em serviços em que os profissionais são, na sua maioria objetores de consciência, o estigma, real ou percebido, tende a ser mais evidente, ocorrendo inclusivamente em relação a colegas, sendo dado que, nos EUA, entre $54 \%$ e $71 \%$ dos profissionais de saúde envolvidos em IG sofreram algum tipo de preconceito (Riedel e Hanschmidt, 2016). O peso do estigma de profissionais e serviços de saúde em relação a colegas que realizam ou não se opõem - à IG é também relevante. Em Portugal 33\% dos médicos, 19\% 
dos enfermeiros, $10 \%$ dos assistentes operacionais e 8,3\% dos assistentes técnicos sentem que o seu trabalho é desvalorizado ou desfavorecido, dentro da sua comunidade, por participarem nos processos de IVG (Reis, 2017; Sociedade Portuguesa de Contraceção, 2018).

Em Portugal existem hospitais em que a generalidade dos profissionais de saúde habilitados para a realização de IG declararam objeção de consciência (Chavkin, Leitman e Polin, 2013), aspeto que se concretiza nas regiões de Lisboa e Vale do Tejo, Açores, Alentejo e nos distritos de Castelo Branco e Guarda por constrangimentos no funcionamento das consultas (DGS, 2016, 2018, 2019; Stifani, Vilar e Vicente, 2018). Nestes casos, o procedimento passa pelo encaminhamento para serviços privados, o que, na grande maioria das situações acontece para o centro da cidade de Lisboa, independentemente da zona de residência da mulher, numa manifesta iniquidade na garantia plena do direito à saúde em situações de aborto. Cabe às políticas públicas reequilibrar os direitos, seja pelas alterações nos enquadramentos legais, tal como verificado em 2007 e aqui demonstrado através da teoria dos fluxos múltiplos, seja pela reestruturação dos serviços, pela regulação da objeção de consciência ou reformulação legislativa (Zampas e Andión-Ibañez, 2012). O presente artigo investiga os preceitos da formulação e da real implementação da lei n.o 16/2007, transposição que pode não ter contribuído para a derradeira eliminação de abortos clandestinos. Para isso importa perceber se o Serviço Nacional de Saúde (SNS) está a garantir acesso generalizado a todas as mulheres que dele queiram usufruir em todo o território nacional e, no caso de não estar, perceber o que profissionais no terreno percecionam em termos da manifestação do eventual desequilíbrio. Da mesma forma que as evidências passadas conduziram à convergência de disposições e consequentes alterações legislativas, a recolha de informação acerca da realidade atual, pode promover importantes referências para debates futuros.

\section{Metodologia}

A metodologia utilizada é dupla. Por um lado, optou-se por uma abordagem quantitativa de análise de dados secundários recolhidos a partir da informação - cujas fontes se encontram identificadas no quadro 1 - oriunda de documentos da DGS e disponibilizada na tese de doutoramento O Aborto como Recurso na Regulação da Fecundidade. Tendências Recentes em Portugal (Baptista, 2017). Por outro lado, foi utilizada uma abordagem qualitativa que se operacionalizou pela análise da informação recolhida a partir de entrevistas e focus group com pessoas de referência no tema em questão. A utilização de entrevistas semiestruturadas é especialmente útil, na medida em que permite um conhecimento próximo da realidade de pessoas de referência na área em estudo. Tais sujeitos, foram selecionados tendo em conta a seu inequívoco conhecimento face ao tema, manifesto pela intervenção durante o período de tempo que vai desde o debate da despenalização, até ao acompanhamento da implementação da lei no terreno. Os seus contributos podem, portanto, abranger uma perspetiva "antes e depois" da mudança legal, bem como permitem 
Quadro 1 Sistematização dos procedimentos metodológicos

\begin{tabular}{|c|c|c|}
\hline & Método quantitativo & Método qualitativo \\
\hline & Fontes de dados & Técnica de entrevista e focus group \\
\hline \multirow{3}{*}{$\begin{array}{l}\text { Descrição } \\
\text { do método }\end{array}$} & $\begin{array}{l}\text { Dados sobre IVG da DGS: } \\
\text { Relatório dos registos de IVG - dados de } 2015 \\
\text { Relatório dos registos das interrupções } \\
\text { de gravidez - dados de } 2016 \text {. } \\
\text { Relatório dos registos das interrupções } \\
\text { de gravidez de } 2017 . \\
\text { Relatório dos registos das interrupções } \\
\text { de gravidez de } 2018 \text {. }\end{array}$ & $\begin{array}{l}4 \text { entrevistas semiestruturadas realizadas: } \\
\text { Dirigente do serviço "Sexualidade em Linha", } \\
\text { Dirigente da ONG UMAR, } \\
\text { Dirigente da Associação para o Planeamento } \\
\text { da Família } \\
\text { Professor universitário, ativista e ex-dirigente } \\
\text { da APF }\end{array}$ \\
\hline & $\begin{array}{l}\text { Dados sobre complicações pós-aborto da DGS: } \\
\text { Relatório das complicações relacionadas com } \\
\text { a interrupção da gravidez } 2009 / 10 \\
\text { Relatório das complicações relacionadas com } \\
\text { a interrupção da gravidez } 2011 / 12 \\
\text { Relatório das complicações relacionadas com a } \\
\text { interrupção voluntária da gravidez } 2013 / 14\end{array}$ & $\begin{array}{l}1 \text { focus group realizado com } 3 \text { profissionais } \\
\text { de saúde: } \\
\text { Médica de hospital público da zona de Lisboa } \\
\text { Médica de hospital público da zona Centro } \\
\text { Enfermeira especialista em unidade de saúde } \\
\text { da zona de Lisboa }\end{array}$ \\
\hline & $\begin{array}{l}\text { Análise dos dados sobre IVG da DGS até } 2013 \\
\text { da tese de doutoramento O Aborto como } \\
\text { Recurso na Regulação da Fecundidade: } \\
\text { Tendências Recentes em Portugal } \\
\text { (Baptista, 2017). }\end{array}$ & $\begin{array}{l}1 \text { Entrevista semiestruturada a mulher com } \\
\text { estória de vida associada a processos de } \\
\text { aborto clandestino, de uma zona na periferia } \\
\text { da cidade de Lisboa. }\end{array}$ \\
\hline
\end{tabular}

aceder a pistas acerca da implementação da lei. As pessoas foram escolhidas tendo em conta a sua relação próxima com o tema, o facto de estarem ligadas ao ativismo no âmbito dos direitos das mulheres, da saúde sexual e reprodutiva e à produção de conhecimento científico nesta área, para além do conhecimento empírico adquirido em trabalho de terreno. A técnica de entrevista presencial é relevante pois, associada a dados formais, permite aceder ao conhecimento de determinados indivíduos (pessoas de referência) em relação ao tópico que se pretende aprofundar, não sendo uma tentativa de corroborar determinadas assunções, mas sim de conhecer "a verdade" que possuem em relação ao assunto (Green e Thorogood, 2018). O mesmo nível de explicação justifica-se no que diz respeito à história de vida recolhida e que descreve a relação de uma mulher com o aborto inseguro. Apesar do reconhecimento de que este contributo permite menos informação relevante para o estudo, a sua utilização pretende adicionar um caráter ilustrativo que pode ser útil à reflexão.

No que diz respeito à técnica de focus group, a mesma justifica-se pois é especialmente eficaz na recolha de informação direta em relação ao um contexto social específico, através de uma entrevista a várias pessoas de um grupo de especialistas, relativamente homogéneo, e que são convidadas a refletir em conjunto sobre um determinado tópico (Robinson, 1999). Neste caso, o convite para a participação na sessão foi dirigido a um conjunto de sete profissionais de saúde que fazem parte do grupo de trabalho que está encarregue de analisar a lei do aborto, embora apenas tenha sido possível contar com a presença de três dessas pessoas, aspeto que constituiu uma manifesta limitação metodológica. Não obstante a limitação decorrente 
da baixa e inesperada adesão, as pessoas que participaram caracterizam-se pelo conhecimento muito próximo da realidade dos serviços de saúde de aborto, não só por motivos decorrentes da própria atividade profissional, mas também por serem, elas próprias, ativistas e membros de organizações que acompanham a temáticas ligadas à saúde sexual e reprodutiva, contribuindo, desta forma, com uma visão abrangente sobre o tópico. A análise da informação decorrente das entrevistas e focus group foi coligida através de métodos de análise de conteúdo (com auxílio do programa NVivo) e foi esta abordagem dupla (qualitativa e quantitativa) que permitiu mitigar os constrangimentos de cada um que os métodos. O quadro 1 sintetiza a metodologia.

A análise da informação foi efetuada de acordo com os seguintes indicadores:

1) Resposta do SNS face às IG nos seus serviços analisada pelo número de IVG em serviços públicos e número de IVG em serviços privados encaminhados de serviços públicos.

2) Capacidade de resposta do SNS nas diversas zonas do país, o qual se pode analisar pelo número mulheres que efetua IVG fora da sua região de residência.

3) Existência barreiras no acesso ao aborto e permanência de abortos clandestinos por esses motivos, aspeto analisado através de informação qualitativa

\section{Discussão de resultados}

Em Portugal entre 2008 e 2013, 46 das 50 instituições de saúde públicas (hospitais na sua maioria) declaravam realizar IVG, embora outros dados indicassem que, nessas instituições, cerca de $80 \%$ dos profissionais de saúde das especialidades envolvidas no procedimento não realizam abortos (Chavkin, Leitman e Polin, 2013). A figura 2 permite ver a evolução do número e percentagem de IG até às dez semanas, por opção da mulher, desde 2008 até 2016.

Segundo os registos da DGS o número de abortos por opção da mulher evoluiu de 18.014 em 2008, atingiu um pico em 2011, de 19.921, e em 2016 foi da ordem dos 15.959 casos. É possível constatar que o número vem decrescendo desde 2011 e que os dados indicam que cerca de $30 \%$ se concentram no setor privado, tendência que se confirma no relatório relativo a 2018, em que 28,7\% das IG ocorreram em serviços privados, num universo de 14.928 casos (DGS, 2019). Apenas uma instituição privada, em Lisboa, é responsável por cerca de $98 \%$ dos procedimentos nos serviços privados, todos os anos. Estes dados, permitem inferir que o SNS não garante, nos seus serviços e de forma generalizada, o acesso ao aborto, na medida em que um terço dos casos se realiza no setor privado. Na realidade a formulação legislativa prevê esta situação e o encaminhamento para serviços alternativos (privados, no caso) parece estar a ser garantido.

Analisando a distribuição dos abortos até às dez semanas por região (figura 3), Lisboa e Vale do Tejo (LVT) é aquela que apresenta números absolutos de IG por opção da mulher mais elevados, no período entre 2008 e 2013, tal como seria de esperar, não só por ser a região mais populosa mas também por albergar a 


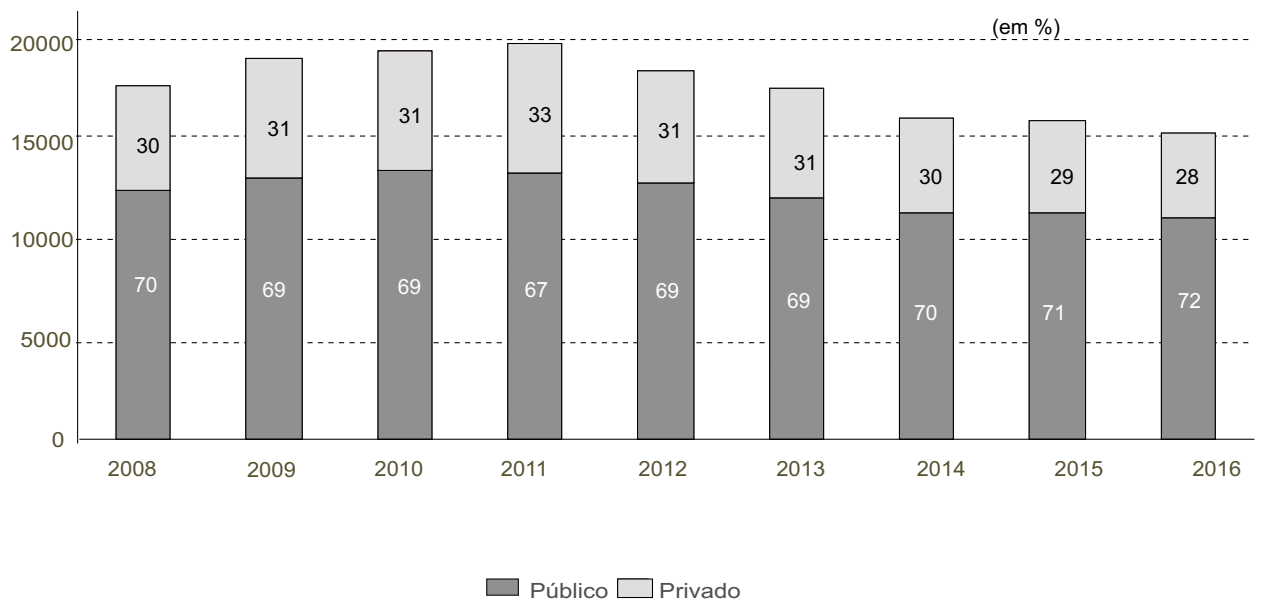

Figura 2 Número de abortos por opção da mulher e percentagem por tipo de serviço Fonte: Direção-Geral da Saúde - Relatórios de Registo da IG da DGS entre 2008 e 2016.

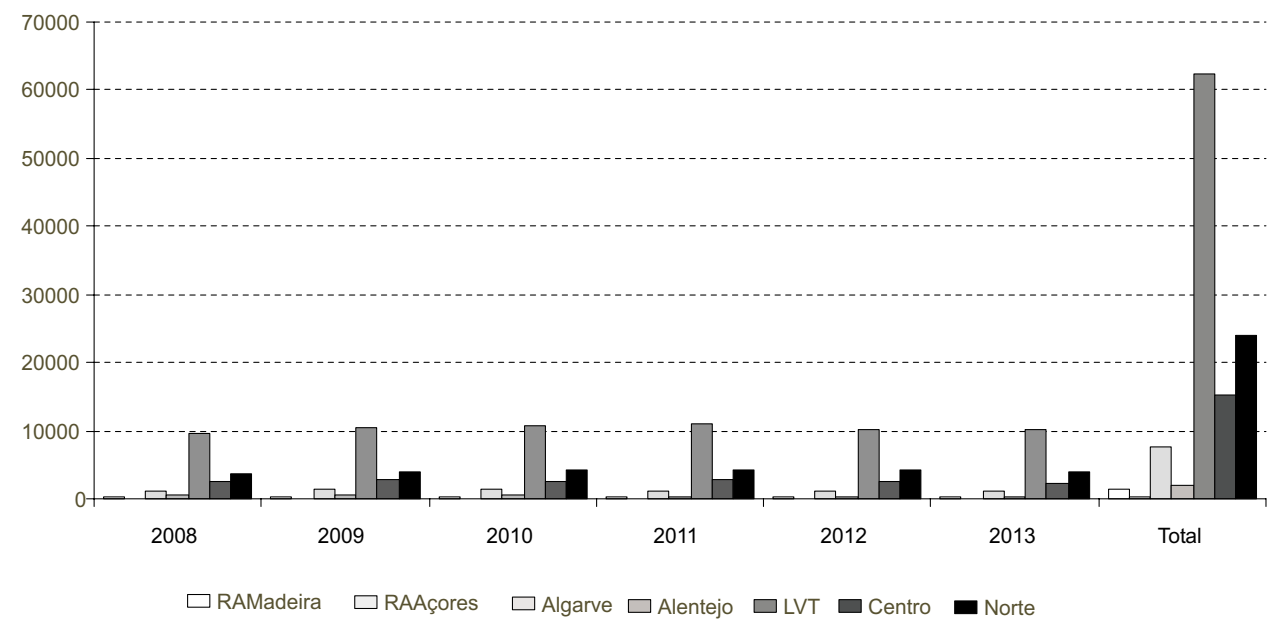

Figura 3 Número total de IVG por opção da mulher em Portugal, por região de 2008 a 2013

Fonte: Direção-Geral da Saúde, dados da plataforma de registo de dados de IG entre 2008 e 2013 , disponibilizados em O Aborto como Recurso na Regulação da Fecundidade: Tendências Recentes em Portugal, de Isabel Baptista (2017). 
instituição privada responsável por cerca de $30 \%$ dos procedimentos em Portugal e cerca de $50 \%$ na região de LVT. Essa instituição recebe grande parte dos encaminhamentos efetuados, não só dentro da região de LVT, como também de outras regiões do país em que os serviços de IG não estão a funcionar, nomeadamente Alentejo, Açores e região Centro.

O quadro 2 resume os dados sobre IG, de algumas instituições de saúde, do território nacional, desde 2008 até 2016. Percebe-se que a IG por opção da mulher se realiza de forma generalizada em todo o território, mas existem diferenças que importa analisar. Se no caso da região Norte e Algarve não parecem existir constrangimentos, percebemos que na região Centro existem duas unidades de saúde públicas que desde 2014 não realizam o procedimento, tendo surgido uma clínica privada para dar resposta a esta situação. No entanto, o número de abortos que esta clínica realiza não parece equivaler aos números de IG realizados nessas duas instituições de saúde nos anos anteriores, o que nos leva a levantar a questão do encaminhamento ou acesso direto a outras instituições de saúde. Uma médica obstetra (focus group realizado a 11 de maio de 2019) indica, a este respeito, que muitas mulheres se deslocam diretamente a Coimbra para a realização da IG, por saberem que na sua zona de residência o serviço não se encontra garantido ou possui tempo de espera longo devido aos poucos profissionais disponíveis para o procedimento, por serem objetores de consciência. Na região de LVT existem quatro hospitais que não realizam IG (nem nunca realizaram, alguns deles), aspeto que afeta diretamente as pessoas do distrito de Santarém e concelhos de Cascais, Oeiras, Sintra e Amadora, havendo um número significativo de mulheres que não está a aceder a este procedimento nos serviços de saúde públicos. Na região do Alentejo, entre 2011 e 2014, os dados mostram que dos dois hospitais centrais da região, um deles não realizava IVG (hospital de Beja), tendo começado a fazê-lo em 2015, e que no outro (de Évora), não existem dados acerca de IVG nas unidades de saúde desde 2008. Nos arquipélagos da Madeira e Açores, em que as deslocações e encaminhamentos são mais complicados, não existe consulta de IVG em todas as ilhas, sendo residual em algumas, como a Ilha Terceira, o procedimento por opção da mulher, o que indica que não devem existir muitos profissionais disponíveis.

Perceber como se garante o acesso nos casos em que o serviço público não o disponibiliza é essencial, até porque, tal como descrito anteriormente, é obrigatório o encaminhamento atempado. A este respeito, os últimos dados da DGS disponíveis, que remontam ao período de 2008 a 2013 (Base de Dados da DGS, 14 de julho de 2015 cit. por Baptista, 2017) permitem verificar precisamente as percentagens de mulheres que realizaram IVG por opção própria, até às dez semanas, fora da sua região de residência.

De acordo com a figura 4, não se verificaram encaminhamentos para fora das regiões Norte, Algarve (exceto em 2011), LVT e Madeira, o que nos indica que nestas regiões ou os serviços funcionam sempre ou os encaminhamentos são efetuados dentro da própria região. Em particular na região de LVT não se verificam situações de mulheres que procuraram outra zona para realizar a IVG, o que se justifica pelo facto de, mesmo nas situações em que os hospitais não efetuam o procedimento, o encaminhamento ser feito dentro da região. Em sentido contrário, as 
Quadro 2 Número absoluto de abortos por opção da mulher por unidade de saúde (apenas as mais relevantes)

\begin{tabular}{|c|c|c|c|c|c|c|c|c|c|c|}
\hline & Instituição de Saúde & 2008 & 2009 & 2010 & 2011 & 2012 & 2013 & 2014 & 2015 & 2016 \\
\hline \multirow{12}{*}{ Norte } & Centro de Saúde de Amarante & 77 & 67 & 142 & 163 & 226 & 172 & 131 & 141 & 110 \\
\hline & $\begin{array}{l}\text { Centro Hospitalar de Entre Douro e } \\
\text { Vouga, E.P.E. - H. de S. Sebastião }\end{array}$ & NA & NA & NA & NA & 268 & 216 & 232 & 210 & 228 \\
\hline & $\begin{array}{l}\text { Centro Hospitalar de S. João, } \\
\text { E.P.E. - H. S. João }\end{array}$ & 346 & 477 & 501 & 597 & 563 & 563 & 500 & 443 & 465 \\
\hline & $\begin{array}{l}\text { Centro Hospitalar de Trás os Montes } \\
\text { e Alto Douro, E.P.E. - H. Vila Real }\end{array}$ & 159 & 183 & 219 & 213 & 174 & 190 & 154 & 143 & 171 \\
\hline & $\begin{array}{l}\text { Centro Hospitalar de Trás os Montes } \\
\text { e Alto Douro, E.P.E. - H. de Chaves }\end{array}$ & 50 & 39 & 56 & 73 & 54 & 39 & 36 & 32 & 33 \\
\hline & $\begin{array}{l}\text { Centro Hospitalar do Alto Ave, } \\
\text { E.P.E. - Unid. Guimarães }\end{array}$ & 278 & 298 & 384 & 406 & 329 & 301 & 268 & 269 & 251 \\
\hline & $\begin{array}{l}\text { Centro Hospitalar do Alto Minho, } \\
\text { E.P.E. - H. Viana do Castelo, St. Luzia }\end{array}$ & 139 & 164 & 131 & 136 & 167 & 198 & 199 & 197 & 162 \\
\hline & $\begin{array}{l}\text { Centro Hospitalar do Médio Ave, } \\
\text { E.P.E. - H. V. Nova de Famalicão }\end{array}$ & NA & NA & NA & 237 & 237 & 254 & 221 & 201 & 133 \\
\hline & $\begin{array}{l}\text { Centro Hospitalar do Porto, } \\
\text { E.P.E. - Maternidade Júlio Diniz }\end{array}$ & 755 & 862 & 1006 & 1026 & 1112 & 1065 & 1007 & 1011 & 1007 \\
\hline & Hospital S. Marcos de Braga & 220 & 277 & 241 & 273 & 293 & 247 & 256 & 284 & 269 \\
\hline & $\begin{array}{l}\text { ULS do Nordeste, } \\
\text { E.P.E. - H. de Bragança }\end{array}$ & 155 & 129 & 167 & 166 & 193 & 175 & 128 & 138 & 155 \\
\hline & $\begin{array}{l}\text { ULS Matosinhos, } \\
\text { E.P.E. - H. Pedro Hispano }\end{array}$ & 274 & 239 & 219 & 231 & 192 & 158 & 169 & 149 & 131 \\
\hline \multirow[b]{3}{*}{ Centro } & Centro Hospitalar Cova da Beira, E.P.E. & 148 & 142 & 164 & 160 & 141 & 102 & 0 & 0 & 0 \\
\hline & Clínica Multimédica & & & & & & & 1 & 37 & 44 \\
\hline & $\begin{array}{l}\text { ULS Castelo Branco, } \\
\text { E.P.E. - H. Amato Lusitano }\end{array}$ & 88 & 106 & 101 & 105 & 107 & 36 & 0 & 0 & 0 \\
\hline \multirow{10}{*}{ LVT } & $\begin{array}{l}\text { Centro Hospitalar Lisboa Norte, } \\
\text { E.P.E. - H.Sta Maria }\end{array}$ & 499 & 566 & 502 & 493 & 438 & 526 & 473 & 454 & 467 \\
\hline & $\begin{array}{l}\text { Centro Hospitalar Lisboa Central, } \\
\text { E.P.E. - Maternidade Dr. Alfredo da } \\
\text { Costa }\end{array}$ & 1406 & 1497 & 1476 & 1555 & 1132 & 875 & 1143 & 1133 & 1159 \\
\hline & Clínica dos Arcos & 5072 & 5780 & 5871 & 6460 & 5607 & 5456 & 4644 & 4449 & 4115 \\
\hline & Hospital de Cascais Dr. José D'Almeida & ND & ND & 180 & 49 & 0 & 0 & 0 & 0 & 0 \\
\hline & Hospital Distrital de Santarém, E.P.E. & 231 & 0 & 0 & 0 & 0 & 0 & 0 & 0 & 0 \\
\hline & Hospital Garcia de Orta & 683 & 856 & 756 & 759 & 762 & 754 & 674 & 638 & 618 \\
\hline & $\begin{array}{l}\text { Hospital Professor Dr. Fernando } \\
\text { Fonseca, E.P.E. }\end{array}$ & 1 & 1 & 0 & 0 & 0 & 0 & 0 & 0 & 0 \\
\hline & Hospital SAMS & 80 & 80 & 104 & 89 & 104 & 84 & 131 & 103 & 134 \\
\hline & $\begin{array}{l}\text { Hospital Vila Franca de Xira, } \\
\text { Dr. Reynaldo dos Santos }\end{array}$ & 456 & 198 & 534 & 412 & 524 & 443 & 286 & 445 & 519 \\
\hline & Hospital Dona Estefânia & 415 & 426 & 245 & 0 & 0 & 0 & 0 & 0 & 0 \\
\hline \multirow[b]{2}{*}{ Alentejo } & $\begin{array}{l}\text { ULS Norte Alentejano, } \\
\text { E.P.E. - H. Dr. José Maria Grande }\end{array}$ & 156 & 130 & 153 & 203 & 177 & 161 & 123 & 160 & 8 \\
\hline & $\begin{array}{l}\text { Centro Hospitalar do Baixo Alentejo, } \\
\text { E.P.E. }\end{array}$ & 320 & 316 & 299 & 0 & 0 & 0 & 0 & 30 & 157 \\
\hline \multirow{2}{*}{ Algarve } & $\begin{array}{l}\text { Centro Hospitalar do Barlavento } \\
\text { Algarvio, E.P.E. - H. Portimão }\end{array}$ & 519 & 539 & 491 & 589 & 478 & 456 & 447 & 463 & 546 \\
\hline & Hospital de Faro & 752 & 790 & 810 & 680 & 745 & 724 & 653 & 610 & 490 \\
\hline \multirow{2}{*}{ Açores } & $\begin{array}{l}\text { Hospital Divino Espirito Santo - Ponta } \\
\text { Delgada }\end{array}$ & 0 & 0 & 0 & 0 & 0 & 0 & 0 & 43 & 118 \\
\hline & Hospital da Horta & 115 & 56 & 57 & 11 & 1 & 0 & 1 & 0 & 5 \\
\hline Madeira & Centro Hospitalar do Funchal & 172 & 245 & 281 & 273 & 257 & 221 & 212 & 184 & 207 \\
\hline
\end{tabular}

Fonte: Direção-Geral da Saúde — Relatórios de Registo da IG da DGS entre (2008 a 2016). 


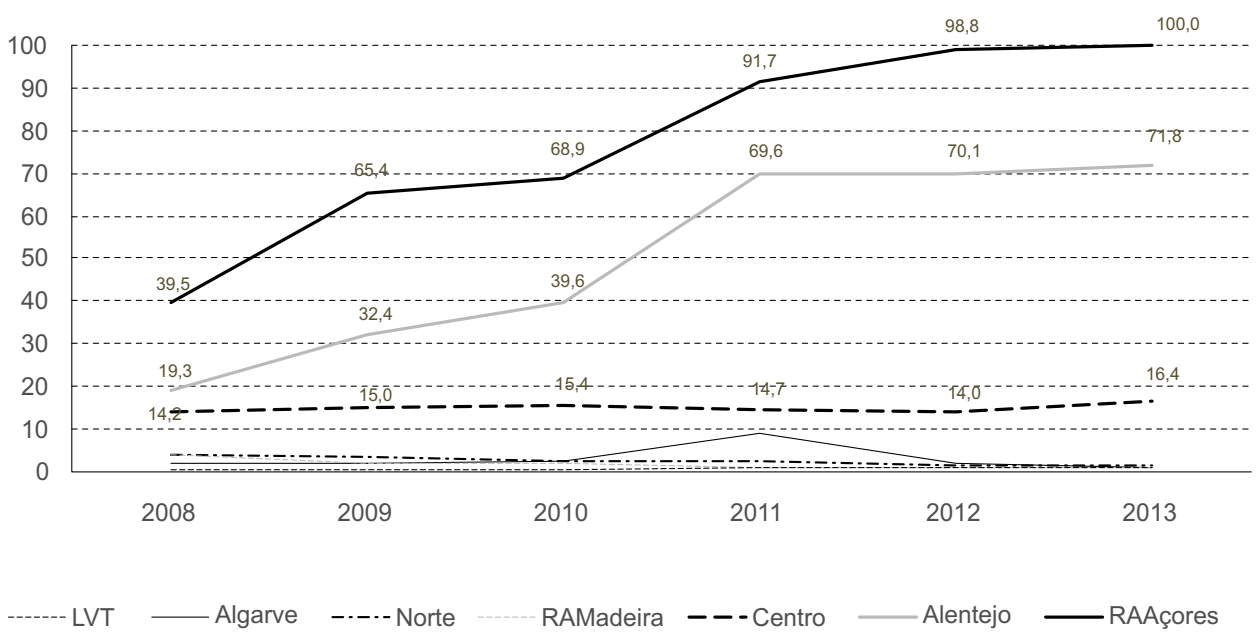

Figura 4 Percentagem de IVG por opção da mulher realizada fora da região de residência

Fonte: Direção-Geral da Saúde, dados da plataforma de registo de dados de IG entre 2008 e 2013 , disponibilizados em O Aborto como Recurso na Regulação da Fecundidade. Tendências Recentes em Portugal, de Isabel Baptista (2017).

regiões Centro, Alentejo e Açores viram o número de mulheres encaminhadas para outras regiões do território aumentar ao longo dos anos em análise, tendo sido, em 2013, encaminhadas para outras regiões do país todas mulheres da Região Autónoma dos Açores. No caso do Alentejo, desde 2008 e até 2013 cada vez menos mulheres residentes na região realizaram IG na área de residência, sendo encaminhadas para outras zonas do país (chegando ao número de $71,83 \%$ ).

A figura 5 indica que as regiões Norte e LVT são aquelas que são recetoras de mulheres oriundas de outras regiões e que, no Alentejo, Algarve, Madeira e Açores, não existe, praticamente, receção de mulheres de outras regiões. Em contrapartida, Norte, LVT e Centro (aqui de forma decrescente) são as regiões em que os serviços de saúde recebem mulheres para IG. As mulheres dos Açores e do Alentejo foram encaminhadas, quase na sua maioria (com algumas exceções residuais para outras regiões) para Lisboa e Vale do Tejo por motivos associados a indisponibilidade dos serviços (figuras 6 e 7). Nestas situações podemos encontrar uma tendência que foi crescendo e estabilizando até em 2013, ano em que cerca de $90 \%$ dos encaminhamentos do Alentejo e cerca de $80 \%$ dos Açores se verificaram por esse motivo. Em 2018, 71\% das mulheres que realizaram IG no setor privado, fizeram-no por encaminhamento de serviços públicos (DGS, 2019).

O SNS não garante o acesso equitativo a IG nos seus serviços a todas as mulheres, dado que grande parte dos procedimentos são realizadas no setor privado e existem mulheres que são encaminhadas da sua região de residência para outras, nomeadamente em Lisboa, aspeto que pode influenciar a decisão de outras mulheres em aceder ao procedimento. Não sendo possível aceder a informação estatística 


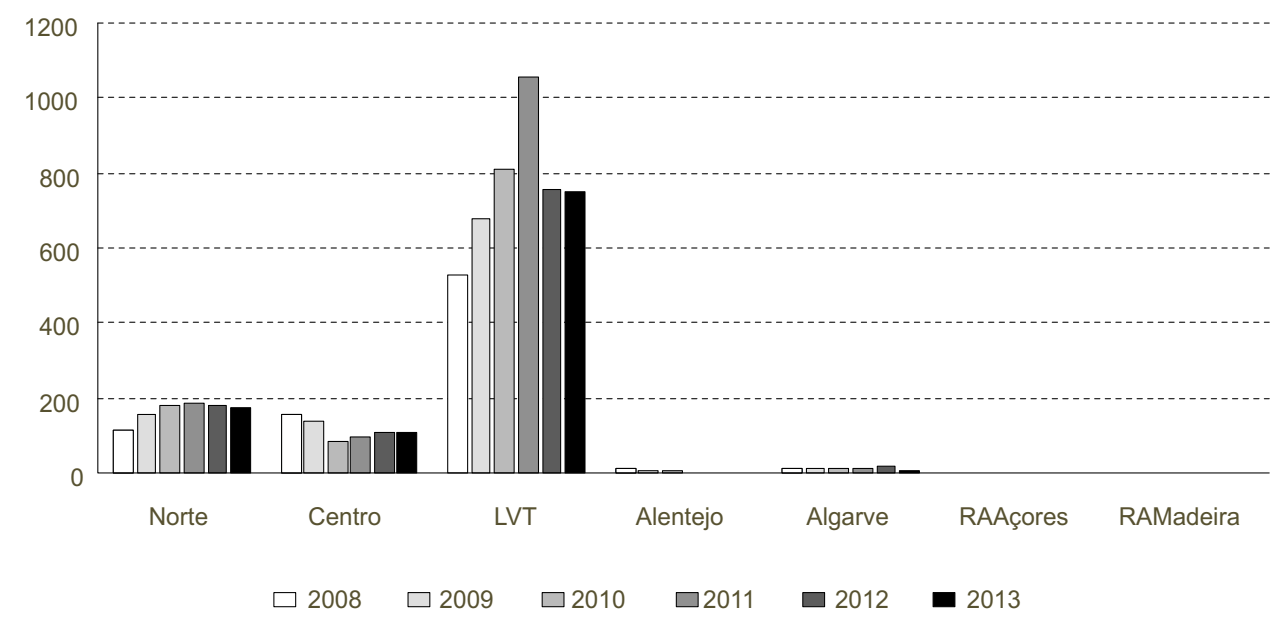

Figura 5 Número absoluto de IVG por opção da mulher, por região e por ano, oriundas de outras regiões

Fonte: Direção-Geral da Saúde, dados da plataforma de registo de dados de IG entre 2008 e 2013 , disponibilizados em O Aborto como Recurso na Regulação da Fecundidade. Tendências Recentes em Portugal, de Isabel Baptista (2017).

que associe estes constrangimentos à opção por abortos clandestinos, a verdade é que a indisponibilidade dos serviços tem um impacto importante na vida destas mulheres. A informação qualitativa ${ }^{4}$ contribui para a análise da relação entre os constrangimentos nos serviços e as escolhas realizadas pelas mulheres em termos do prosseguimento ou interrupção segura da gravidez, bem como para o conhecimento acerca da implementação. Como mencionado, estes dados foram recolhidos através de técnicas de entrevista e focus group a pessoas com percurso profissional e ativismo na área do aborto com contributos incontornáveis no processo histórico, legislativo e social, que conduziu à realidade atual.

Os entrevistados manifestam a ideia de que o direito ao aborto seguro inserido no SNS é uma conquista civilizacional, dado que nenhuma mulher morreu ou foi criminalizada por procedimentos de aborto inseguro. Do ponto de vista formal, a implementação da lei está a acontecer, verificando-se o cumprimento dos pressupostos da sua formulação, para além de que uma situação legal menos restritiva produz conhecimento sobre o tema, permitindo situar a evolução e constrangimentos, algo que antes de 2007 era praticamente impossível. Em relação à questão do encaminhamento para instituições privadas é unânime que o processo funciona de forma plena e, apesar de alguns serviços públicos não realizarem IG, encaminhando as mulheres, outros houve que se organizaram desde o primeiro dia para começar a realizar IG por opção

4 A informação apresentada com base nas entrevistas e focus group será completada com citações diretas das mesmas no sentido de ilustrar melhor as ideias apresentadas. 


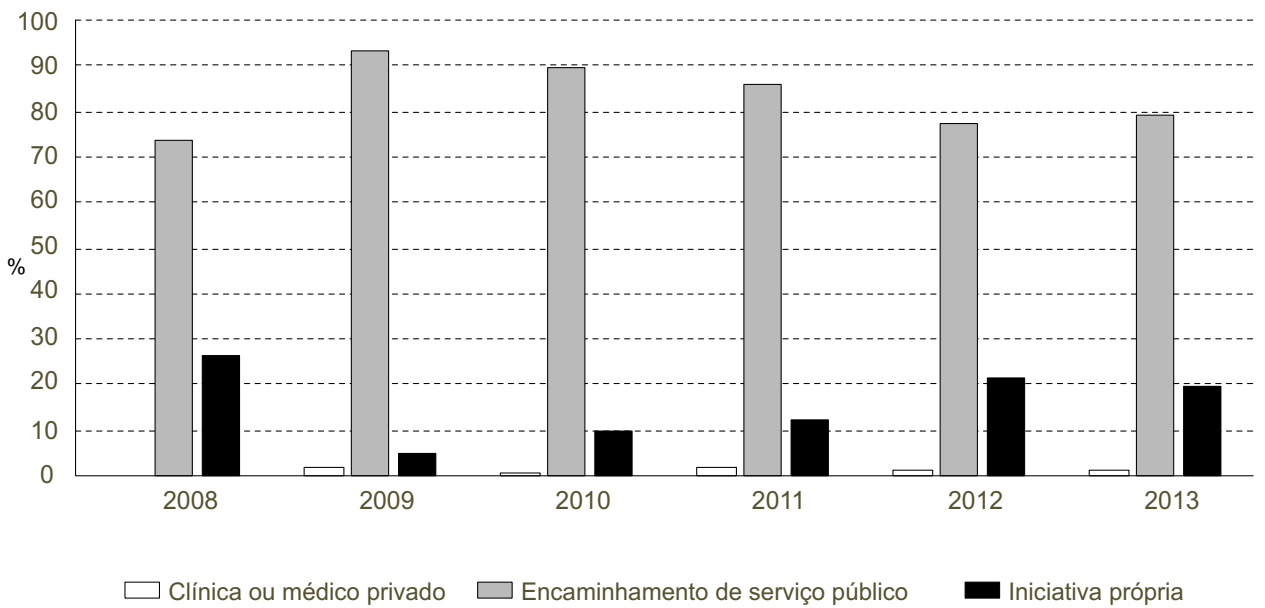

Figura 6 Razões para o deslocamento de mulheres oriundas dos Açores para realização de IVG por opção da mulher entre 2008 e 2013

Fonte: Direção-Geral da Saúde, dados da plataforma de registo de dados de IG entre 2008 e 2013 disponibilizados em O Aborto como Recurso na Regulação da Fecundidade. Tendências Recentes em Portugal, de Isabel Baptista (2017).

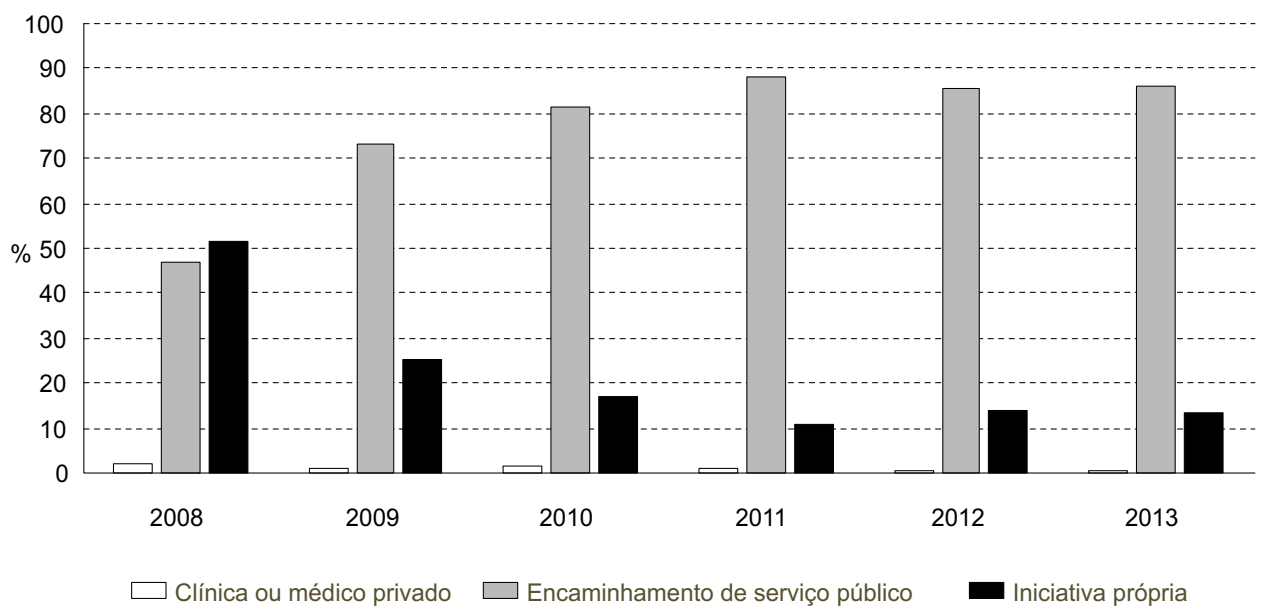

Figura 7 Razões para o deslocamento de mulheres oriundas do Alentejo para realização de IVG por opção da mulher entre 2008 e 2013

Fonte: Direção-Geral da Saúde, dados da plataforma de registo de dados de IG entre 2008 e 2013, disponibilizados em O Aborto como Recurso na Regulação da Fecundidade. Tendências Recentes em Portugal, de Isabel Baptista (2017). 
da mulher. Em particular, hospitais em Lisboa e serviços no Algarve e no Norte do país conseguiram organizar-se de forma a garantir que o acesso fosse mais igualitário, o que demonstra que uma reorganização de equipas e serviços permite ultrapassar constrangimentos. No entanto, para além da questão da objeção de consciência, que constrange o funcionamento dos serviços, existem outras situações que se podem constituir como entraves à concretização do aborto por opção da mulher.

\section{Constrangimentos e iniquidade no acesso aos serviços}

Para os entrevistados a lei n. ${ }^{\mathrm{o}}$ 16/2007 merece revisão. Em primeiro lugar, o facto de a redação constar do Código Penal atribui ao procedimento e a quem o pratica um caráter estigmatizante. O estigma é, aliás, um aspeto central neste tema e merece uma análise cuidada do seu impacto na implementação da lei. A este propósito, a forma como a sociedade representa a mulher que faz um aborto, mas também as representações que os profissionais de saúde têm em relação aos colegas que participam no processo potenciam os efeitos de outras barreiras.

\section{Estigma e preconceito}

O estigma social e legal em relação à mulher que recorre ao aborto está presente em vários momentos do procedimento. Desde logo, o período de reflexão obrigatório de três dias, presente na lei portuguesa, pode atuar como mecanismo moralizador da mulher que inicia um processo de IG. Esta obrigatoriedade indica que o aborto não é um ato médico como os outros e deve ser tratado de forma diferente, o que constitui um elemento que perpetua preconceitos. Aliás, em 2015 o movimento de cidadãos "Pelo Direito a Nascer" (Iniciativa Legislativa de Cidadãos, 2015) exigiu que nesse período de reflexão a mulher passasse por um acompanhamento psicossocial obrigatório, o que aumentaria o estigma da sua decisão. Existem, adicionalmente, profissionais de saúde que manifestam uma predisposição moralizadora sobre as mulheres, promovendo deliberadamente dificuldades acrescidas no acesso ao aborto (Autorino, Mattioli e Mencarini, 2020; Kaposy, 2010). Segundo os profissionais de saúde entrevistados, tal verifica-se também da parte de profissionais não diretamente envolvidos e do pessoal administrativo com quem a mulher pode ter contacto. Por outro lado, o impacto do estigma encontra-se ao nível da objeção de consciência e implicações que tem no funcionamento dos serviços, bem como através das relações entre diferentes profissionais. Neste aspeto, a formulação legislativa fomenta a perpetuação do estigma nomeadamente pelo facto de a lei n. ${ }^{-}$ 16/2007 determinar, em procedimentos de IG, que um profissional de saúde supervisione o processo de datação feito por um seu colega. Acresce ainda o facto de, junto da comunidade clínica, ser assumido que a área da saúde sexual e reprodutiva, em geral, e os procedimentos de IG, em particular, são atividades menosprezadas e consideradas atos menores, o que potencia mais situações de objeção de consciência. Na realidade, muitos dos profissionais envolvidos em IG sofrem ou já sofreram algum tipo de marginalização dentro da sua classe profissional, o que os torna menos disponíveis a realizá-lo, alegando, nessas situações, objeção de consciência. 


\section{Citações sobre o estigma e preconceito:}

1) ... não estamos numa situação em que se olha para a mulher como uma pessoa honesta e competente na sua decisão. (Dirigente APF Lisboa)

2) Mas quando a pessoa diz que está determinada e decidida não percebo por que motivo tem de fazer esta espera obrigatória. Questiono se não é um bocadinho pôr em causa a verdadeira capacidade da mulher em decidir. (Idem)

3) E aqui está o estigma. Se eu vou fazer um aborto os olhares estão sobre mim. (Médica obstetra de Lisboa)

4)... o estigma está na lei quando diz que tem de haver dois médicos (ou profissional), portanto a pessoa que fizer a consulta prévia tem de ser diferente daquela que fizer a datação. (Idem)

5) ... tem a leitura do estigma social, o facto de as pessoas saberem que são mal vistas por irem fazer o aborto também condiciona aquilo que a pessoa pensa e faz. (Idem)

6) Quando há duas pessoas que têm de atestar que aquela pessoa tem menos de 10 semanas aí está o estigma da lei. (Idem)

7) As pessoas que são objetoras à decisão são muito mais perigosas e penalizadoras da mulher. E são destrutivas. (Idem)

8) A questão da interrupção era quase como se não fossem coisas médicas. (Médica obstetra de Coimbra)

9) Eu tenho sempre aquele olhar de que estou a fazer algo fora da lei. Isto cria barreiras, é como se fosse uma auditoria interna. (Idem)

10) Dentro da nossa especialidade as coisas não são iguais. E nós pertencemos a uma sociedade científica e nos eventos o nosso primeiro espaço para as coisas sobre planeamento familiar num evento de 4 dias era domingo de manhã no final da reunião. Portanto, não estamos a falar de estigmatização? Estamos. (Idem)

11) No outro dia estava de urgência e estava lá por causa de uma outra senhora. Estava lá uma senhora a marcar uma consulta porque tinha feito uma interrupção e a secretária, que nem sabia quem era a mulher, disse-me logo: esta mulher usa a IG como método contracetivo. (Idem)

12) Nos centros de saúde mudavam tanto que depois não conheciam as pessoas. E portanto quase todas tinham de expor aquilo tudo. (Enfermeira especialista de Lisboa) 
13) ... às vezes ouve-se dizer que o profissional faz uma lavagem cerebral. (Idem)

14) Há uns tempos tivemos uma jovem a informar que, nem era um médico, era uma enfermeira, que barrou tudo aquilo que podia para ela não continuar com o processo. Isto não pode acontecer. (Dirigente do serviço "Sexualidade em Linha")

15) Nós estamos a analisar a situação do ponto de vista de um centro urbano mas se pensarmos na parte rural a questão da confidencialidade é garantida pelos técnicos mas a comunidade está atenta e isto é um constrangimento. (Idem)

16) ... resistência que os profissionais têm aos abortos de repetição (dirigente APF Lisboa)

Existem, como se viu, fatores que afetam os serviços e colocam as mulheres numa posição de fragilidade social e emocional, e tendem a obrigá-las a deslocar-se da sua zona geográfica para a realização de IG (o que acarreta custos e tempo), podendo também levá-las a escolhas menos adaptativas, como abortos inseguros ou prosseguimento de gravidezes não desejadas. Estigma e preconceito, intersetados com outras barreiras concorrem para o agravamento da iniquidade. Verificou-se previamente que a idade gestacional, a obrigatoriedade de realização do procedimento em hospitais, a necessidade de validação do procedimento por dois profissionais, a objeção de consciência, os períodos de espera obrigatórios, a autorização de partes terceiras ou ainda o acompanhamento psicossocial obrigatório (Culwell e Hurwitz, 2013; Finer e Fine, 2013; Levels, Sluiter and Need, 2014) são aspetos que constituem barreiras ao acesso e que é possível encontrar na realidade portuguesa. $\mathrm{O}$ quadro que se segue sistematiza a informação recolhida a partir das entrevistas realizadas para posterior discussão.

Um dos aspetos mais amplamente debatidos prende-se com o limite das dez semanas para a realização da IVG. Esta determinação implica que o tempo para a realização do procedimento se torna demasiado curto para além de ser complexo e implicar múltiplas consultas, aspetos que podem colocar mulheres em situação de ilegalidade, em especial aquelas que detetem a gravidez tardiamente. A necessidade de participar em consultas e exames múltiplos e em diferentes serviços, associada ao período de reflexão obrigatório, faz com que o procedimento se complexifique e pode contribuir para que se atinja rapidamente o prazo legal das dez semanas. Naturalmente que estes fatores tendem a afetar mulheres de zonas geográficas em que os serviços de saúde não têm a consulta a funcionar, bem como localidades onde existam mulheres com mais características de vulnerabilidade, tais como mulheres imigrantes, jovens ou em situação de pobreza. O relato que se segue é o de uma mulher de uma zona periférica da cidade de Lisboa e ilustra essa mesma situação.

... primeiro ia fazer uma análise ao sangue num laboratório com uma credencial da médica. A médica dá-te uma credencial para ires fazer uma análise ao sangue e uma ecografia para se ver o tempo. E nem sempre consegues fazer uma ecografia de urgência. Se tiveres dinheiro, fazes no mesmo dia, há várias clínicas privadas. E se não tiveres? Tens de fazer através do SNS e nem sempre há vagas. Isto tens de ir ao centro de 
Quadro 3 Aspetos que interferem com a iniquidade no acesso, sua manifestação e impacto geográfico

\begin{tabular}{|c|c|c|}
\hline Constrangimentos & Manifestação do problema ${ }^{(1)}$ & Região onde se manifesta \\
\hline $\begin{array}{l}\text { Serviços de saúde sem consulta de } \\
\text { IG por objeção de consciência }\end{array}$ & $\begin{array}{l}\text { Necessidade de deslocação para } \\
\text { outra região } \\
\text { Ausência de comparticipação nas } \\
\text { deslocações } \\
\text { Deslocações múltiplas } \\
\text { Equipas sem profissionais } \\
\text { disponíveis ou com profissionais } \\
\text { estigmatizados }\end{array}$ & $\begin{array}{l}\text { Região Centro (Leiria, zona da } \\
\text { Cova da Beira); Açores; Alentejo; } \\
\text { alguns concelhos da região de } \\
\text { Lisboa (Oeiras, Sintra, Amadora, } \\
\text { Cascais) }\end{array}$ \\
\hline $\begin{array}{l}\text { b) Esperas longas devidas: } \\
\text { - Período de reflexão obrigatório } \\
\text { - Excesso de burocracia } \\
\text { - Necessidade de várias consultas } \\
\text { (três do processo de IVG, para } \\
\text { exames, e encaminhamento) }\end{array}$ & $\begin{array}{l}\text { 1. Possibilidade de ultrapassar } \\
\text { o período legal de } 10 \text { semanas } \\
\text { 2. Deslocações múltiplas } \\
\text { 3. Consequências emocionais }\end{array}$ & $\begin{array}{l}\text { Generalizado } \\
\text { Açores (deslocação por falta de } \\
\text { serviços de aborto em todas as } \\
\text { ilhas, agravado pelo período de } \\
\text { espera de } 3 \text { dias) }\end{array}$ \\
\hline c) Prazo das 10 semanas limitado & $\begin{array}{l}\text { 1. Maior possibilidade de ficar fora } \\
\text { do prazo/da lei } \\
\text { 2. Decorre de uma decisão } \\
\text { meramente política }\end{array}$ & $\begin{array}{l}\text { Generalizado mas mais marcante } \\
\text { nas situações em que as mulheres } \\
\text { tenham de fazer múltiplas } \\
\text { deslocações }\end{array}$ \\
\hline $\begin{array}{l}\text { d) Desconhecimento acerca da } \\
\text { legalidade do procedimento em } \\
\text { particular em comunidades } \\
\text { migrantes }\end{array}$ & $\begin{array}{l}\text { 1. As mulheres podem recorrer aos } \\
\text { abortos inseguros }\end{array}$ & $\begin{array}{l}\text { Zonas geográficas com } \\
\text { comunidades mais fechadas, } \\
\text { isoladas ou imigrantes. }\end{array}$ \\
\hline $\begin{array}{l}\text { e) Datação feita por dois } \\
\text { profissionais }\end{array}$ & $\begin{array}{l}\text { Estigmatização e supervisão entre } \\
\text { colegas } \\
\text { Complexificação dos recursos } \\
\text { humanos necessários para o } \\
\text { procedimento }\end{array}$ & Generalizado \\
\hline
\end{tabular}

(1) Estes constrangimentos afetam todas as mulheres, embora com incidência maior em grupos vulneráveis: mulheres estrangeiras, mulheres jovens ou mulheres com pouca capacidade para a resolução de problemas ou desinformadas.

saúde, depois vir para Amadora para ir fazer os exames, depois tens de voltar ao posto médico apresentar os resultados. E aí a médica, nesse dia, é que manda um fax do posto médico para a clínica, depois ficas à espera dois ou três dias que a clínica te ligue para te apresentares. Então tens de te deslocar a Lisboa. E depois tens de te deslocar outra vez a Lisboa porque o primeiro dia é só para verem os resultados dos exames que tu já levas. E no segundo dia em que lá voltas e que fazem mesmo o aborto. Autocarro para a Pontinha, são 2,5 só para baixo, mais 2,5 para cima. Depois ainda tens o metro. Depois tens de subir aquela ladeira toda a pé na Av. da Liberdade. Mas gastas à vontade 10/15 euros. Uma vez. E tens de ir duas vezes lá. Fora o que gastas para vir para a Amadora que são 3 euros e tal para ir e 3 euros e tal para voltar para fazer ecografia e verem o tempo. Isto leva tudo à volta de 15 dias. E mais os dias de trabalho que perdes. Imagina que ganhas aí 15 ou 20 euros por dia que é o que anda aí a média. Perdes um dia para fazer exames. Logo 20 euros, perdes o dia que vais à clínica, mais 20 euros e perdes o dia em que que vais fazer a cirurgia. São mais 20. 60. Fora alguns 20 ou 30 que já gastaste em transportes. Fora o tempo que perdes no posto médico e corres o risco de chegar lá e o médico dizer que já passou o tempo. 
Existem mulheres para as quais o acesso ao aborto seguro é mais dificultado do que para outras e, como vimos, são muitas vezes as posições ideológicas dos profissionais que afetam o funcionamento dos serviços. Tal evidência reveste-se de especial gravidade quando se percebe que os motivos que estão por trás da objeção de consciência nem sempre são ideológicos ou relacionados com a ética pessoal. Há situações em que os serviços, em particular pela ação dos seus diretores, se organizam para que não exista nenhum profissional disponível para a realização de abortos, fechando as consultas. Nestas situações, descritas como objeção ao trabalho, existe uma manipulação da possibilidade constitucional de exercício do direito à objeção de consciência, aspeto que demonstra a necessidade da sua regulação no sentido da garantia de universalidade do SNS.

Citações sobre objeção de consciência:

1) Há outros objetores de consciência que não se querem envolver na IVG por acharem que é um ato menor comparativamente a outros procedimentos na área da ginecologia e obstetrícia. (Professor e ex-dirigente APF)

2) Só fazem objeção de consciência em relação às IVG a pedido da mulher que é o maior número e que me leva aqui a considerar que existe uma conveniência de serviço nessa objeção de consciência. (Idem)

3) A OC foi, em muitos locais é um pretexto para se fechar a consulta. Eu não vou dizer quais foram os hospitais e até foram dois. (Médica obstetra de Lisboa)

4) Há os objetores de consciência que são objetores ao trabalho e portanto se fizerem IG é mais uma coisa que fazem. (Idem)

5) Eles querem fechar a consulta mas o hospital não se quer responsabilizar, metem todos o papel da OC e fecham.

6) Acho que é objeção ao trabalho (em relação à posição de alguns colegas). (Médica obstetra, Coimbra)

7) Sim, eu sei de um hospital em que a própria direção do serviço pressionava as pessoas para não terem chatices punham o papel da objeção. (Idem)

Se com este problema concorrerem os outros já descritos, existem indícios de que estejam criadas condições justificadas para intervir nesta matéria. Funcionamento ou não dos serviços, tempos de espera demasiado longos decorrentes do período de reflexão e burocracia, limite de dez semanas demasiado curto e necessidade de validação do procedimento por dois profissionais, bem como a necessidade de organização das equipas e o estigma que nelas abunda são aspetos que parecem penalizar mulheres que se encontram em situação de desfavorecimento. 
Citações sobre o aborto clandestino:

1) Se dificultamos e os acessos não são fáceis, é bem possível que aconteça a questão do aborto clandestino. (Dirigente APF Lisboa)

2) Eu acho que a acessibilidade pode fomentar o aborto clandestino. (Médica obstetra, Coimbra)

3) Continua a haver porque a acessibilidade não é boa. (Idem)

4) Se me perguntar se há aborto clandestino em Portugal? Há de certeza, mas nunca mais voltámos a ouvir. (Idem)

5) (sobre os efeitos da OC) Sim e muitas vezes pode ser motivo para deixarem de aceder a um serviço de aborto seguro e eventualmente meterem-se em zonas de aborto inseguro. (Professor e ex-dirigente APF)

6) É um buraco negro e são práticas que é muito difícil percecionar. As mulheres têm tendência a ocultar esta situação porque de facto não são práticas legais. Mas sim, há testemunhos e eu já vi nomeadamente uma médica de família que relatou casos de aborto inseguro em suas utentes ali na região da Amadora. (Idem)

O que a informação recolhida parece sustentar é que os constrangimentos elencados impactam de tal forma que, muito provavelmente, existem mulheres que recorrem a abortos clandestinos. $\mathrm{O}$ relato que se segue ilustra derradeiramente essa possibilidade, apesar de não existirem registos clínicos de complicações decorrentes de abortos clandestinos desde 2007 (DGS, 2011, 2013, 2015). Tal como disse uma das entrevistadas: "ficaram os melhores a fazer os abortos clandestinos".

Então o dinheiro que gastam em transportes, o tempo que vão perder e tudo, preferem comprar os comprimidos. E fazem logo. E acabam por nunca saber o tempo. Eu já fiz e conheço tanta gente que já fez. Porque tem saída. E nos bairros sociais ainda mais. Então eu moro num bairro e tenho acesso a tudo vou mas é fazer em casa. Se eu sei fazer, se já ajudei tanta gente a fazer e eu já fiz também. Porque é que não hei de fazer? E fiz mas levei dois dias a expulsar o feto. Mas sei de montes de casos. Uma que fez um aborto ao mesmo tempo que eu, até fui eu que lhe arranjei os comprimidos, que não aguentou as dores e foi para o hospital e apresentaram queixa dela. É crime.

É lá no bairro. 10 euros cada um. Cada comprimido. Uma caixa deve ficar à volta de 6 ou 7 euros mas só consegues comprar com receita médica porque aquilo são comprimidos para o estômago, pagas 10 euros cada um. E depois aquilo é, se tiveres até aos quatro meses basta seis comprimidos. Conheces situações de mulheres que tenham feito aborto clandestino mesmo estando dentro do prazo legal? Sim. Há mulheres que 
preferem comprar comprimidos e fazer em casa. Então preferem arranjar dinheiro aqui e ali e arranjar os comprimidos. E isso nunca vai acabar, isso dos comprimidos. Se a lei não mudar, os comprimidos nunca acabam.

\section{Conclusão}

É abusivo traçar uma linha de causalidade inequívoca entre as barreiras no acesso à IG, seu impacto no funcionamento dos serviços e a opção pelo aborto clandestino, nomeadamente tendo em conta a dimensão dos dados qualitativos aqui analisados, manifestamente insuficientes para a produção de generalizações. Não obstante e apesar de ser delicado o debate em torno de eventuais falências na implementação de uma lei que garante direitos e saúde a tantas mulheres, existem evidências importantes que é possível apontar, nomeadamente as que remetem para a questão do acesso. A proposta do presente artigo era a de analisar os mecanismos de implementação da lei n. ${ }^{\circ}$ 16/2007, à luz de uma contextualização em que o seu agendamento e formulação foram possíveis, após diversos momentos e contributos amplamente explanados neste texto. Foram descritas pistas empíricas, bem como evidências de múltiplas análises teóricas, que direcionam a análise de barreiras à implementação da lei, as quais se procuraram sinalizar através da recolha de dados estatísticos e relatos de pessoas de referência na área. É o fruto dessa análise que agora se resume.

A primeira evidência é a de que a objeção de consciência interfere na organização das equipas e no funcionamento das unidades de saúde, levando a que muitas mulheres sejam obrigadas a deslocar-se para instituições privadas fora da sua região de residência. A acessibilidade torna-se, portanto, desigual no território nacional e/ou entre localidades, afetando particularmente mulheres em situação de desfavorecimento (mulheres imigrantes, em piores situações económicas, mulheres mais novas, etc.), o que é uma evidência de interseção de desigualdades múltiplas, com origem no género. Esta iniquidade é agravada por outras questões da formulação legal do procedimento de IG. Em segundo lugar, torna-se evidente, através da sistematização dos contributos de pessoas de referência na área, que o limite de dez semanas é curto em muitas situações, que o período de três dias obrigatórios para reflexão (potencialmente discriminatório) e o estigma em relação às mulheres e aos profissionais interferem negativamente com a acessibilidade e com as escolhas feitas pelas mulheres. A conjugação destes diversos aspetos, corroborados pelo enquadramento teórico apresentado, podem levar a que existam mulheres, de determinadas regiões do país, que podem continuar a recorrer a abortos clandestinos, tal como se verificava antes de 2007. Esta possibilidade é descrita pelos profissionais entrevistados e verificada pela referência retirada da história de vida.

Apesar destas evidências não se pode deixar de referir as fragilidades que a abordagem apresenta, nomeadamente em termos da secundarização dos dados analisados e da limitada participação de profissionais nos focus group realizado.

No entanto, de acordo com os dados qualitativos recolhidos, bem como da análise dos dados estatísticos disponíveis, podem ser refletidas mudanças em 
áreas que passam pela regulamentação da objeção de consciência de profissionais de saúde, nomeadamente pelo escrutínio acerca dessa posição, pelo desenho de mecanismos de mitigação de outras barreiras já descritas e que passam, em grande medida, pela organização dos serviços e equipas clínicas, bem como pelo processo necessário de generalização do acesso ao aborto. De acordo com diferentes autores, o compromisso de um SNS universal funda-se na ausência de discriminação e de danos e encargos para as pessoas (Ortiz, 2017; Wicclair, 2011; Chavkin, Leitman e Polin, 2013). Assim, as virtudes que eventualmente se podem encontrar neste artigo passarão pela chamada de atenção para uma realidade que se previu estar erradicada com a alteração legislativa de 2007, mas que agora pode motivar a assunção de responsabilidade na procura de alternativas para que nenhuma mulher pondere sequer recorrer a abortos clandestinos. Estas alternativas passam pela valorização da mulher e dos profissionais, pela eliminação dos efeitos do estigma e preconceito em prol da vivência social plena e do bem-estar comum, centrais nas medidas de políticas públicas em saúde. É pela melhoria sucessiva do SNS e na garantia de transversalidade e equidade no acesso de todas as mulheres a IG segura que se contraria a penalização de muitas mulheres que pretendem aceder a cuidados e serviços de saúde.

\section{Referências bibliográficas}

Alves, M., A. C. Santos, C. Barradas, e M. Duarte (2009), “A despenalização do aborto em Portugal - discursos, dinâmicas e acção colectiva: os referendos de 1998 e 2007", Oficina do CES, 320 (número temático).

Autorino, T., F. Mattioli, e L. Mencarini (2020), “The impact of gynecologists' conscientious objection on abortion access", Social Science Research, 87 (outubro). DOI: https://doi.org/10.1016/j.ssresearch.2020.102403

Baptista, I. M. R. (2017), O Aborto como Recurso na Regulação da Fecundidade? Tendências Recentes em Portugal, Lisboa, Iscte-IUL.

Berer, M. (2004), "National laws and unsafe abortion: the parameters of change", Reproductive Health Matters, 12 (24), pp. 1-8. Disponível em: https://doi.org/10.1016/S0968-8080(04)24024-1 (última consulta em maio de 2021).

Blofield, M. (2008), “Women's choices in comparative perspective: abortion policies in late-developing catholic countries", Comparative Politics, 40 (4), pp. 399-501.

Boland, R., L. Katzive, e B. R. Boland (2008), “Developments in laws on induced abortion?: 1998-2007", International Family Planning Perspectives, 34 (3), pp. 110-120.

Brown, P., and S. Zavestoski (2004), "Social movements in health: an introduction", Sociology of Health $\mathcal{E}$ Illness, 26 (6), pp. 679-694. DOI: https://doi.org/10.1111/j.0141-9889.2004.00413.x

Cartwright, A. F., M. Karunaratne, J. Barr-Walker, N. E. Johns, e U. D. Upadhyay (2018), "Identifying national availability of abortion care and distance from major US cities: systematic online search", Journal of Medical Internet Research, 20 (5). DOI: https://doi.org/10.2196/jmir.9717 
Center for Reproductive Rights (2019), By the Numbers? The Legal Status of Abortion Worldwide, pp. 1-4.

Chavkin, W., L. Leitman, e K. Polin (2013), “Conscientious objection and refusal to provide reproductive healthcare: a White Paper examining prevalence, health consequences, and policy responses", International Journal of Gynecology and Obstetrics, 123 (supl. 3). DOI: https://doi.org/10.1136/jfprhc-2014-100886

Chavkin, W., L. Swerdlow, e J. Fifield (2017), "Regulation of conscientious objection to abortion", Health and Human Rights, 19 (1), pp. 55-68.

Código Deontológico, inserido no Estatuto da OE, republicado como anexo pela lei n. ${ }^{\circ} 111 / 2009$, de 16 de Setembro (2009).

Costa, A. (2012), Desigualdades Sociais Contemporâneas, Lisboa, Mundos Sociais.

Culwell, K. R., e M. Hurwitz (2013), “Addressing barriers to safe abortion”, International Journal of Gynecology and Obstetrics, 121, pp. 16-19. DOI: https://doi.org/10.1016/j.ijgo.2013.02.003

Cunningham, F. G., K. J. Leveno, S. L. Bloom, C. Y. Spong, J. S. Dashe, B. L. Hoffman, B. M. Casey, and J. S. Sheffield (2014), Williams Obstetrics, Nova Iorque, McGraw-Hill Education (24. a edição).

De Zordo, S. (2016), "Abortion, stigma and conscientious objection: experiences and opinions of gynecologists in Italy and Catalonia", Medicina Nei Secoli, 28 (1), pp. 195-247. Disponível em: http://europepmc.org/abstract/MED/28854330 (última consulta em maio de 2021).

DGS - Direção-Geral de Saúde (2011), Relatório de Análise das Complicações Relacionadas com a Interrupção da Gravidez, 2009 - 2010. Consultado em: www.saudereprodutiva.dgs.pt (já não disponível).

DGS - Direção-Geral de Saúde (2013), Relatório de análise das complicações relacionadas com a interrupção da gravidez $2011-2012$.

DGS - Direção-Geral de Saúde (2015), Relatório de Análises das Complicações Relacionadas com a Interrupção Voluntária da Gravidez 2013-2014. Disponível em: http://www.apf.pt/sites/default/files/media/2016/relatorio_complicacoes-ig_2013-2 014_final.pdf (última consulta em maio de 2021).

DGS - Direção-Geral de Saúde (2016), Relatório dos Registos dos Dados de 2015 Direção de Serviços de Prevenção da Doença e Promoção da Saúde Divisão de Saúde Sexual , Reprodutiva, Infantil e Juvenil.

DGS - Direção-Geral de Saúde (2018), Relatório dos Registos das Interrupções de Gravidez - Dados de 2016.

DGS - Direção-Geral de Saúde (2019), Relatório dos Registos das Interrupções de Gravidez de 2018.

Doran, F. M., e J. Hornibrook (2016), “Barriers around access to abortion experienced by rural women in New South Wales, Australia", Rural and Remote Health, 16 (1). DOI: https://doi.org/10.22605/RRH3538

Doran, F., e S. Nancarrow (2015), "Barriers and facilitators of access to first-trimester abortion services for women in the developed world: a systematic review", Journal of Family Planning and Reproductive Health Care, 41 (3), pp. 170-180. DOI: https://doi.org/10.1136/jfprhc-2013-100862 
EIGE - European Institute for Gender Equality (2017), Gender Equality Index 2017. Measuring Gender Equality in the European Union 2005-2015. Main Findings, Bruxelas, Publications Office of the European Union. DOI: https://doi.org/10.2839/770576

Fiala, C., e J. H. Arthur (2014), "'Dishonourable disobedience' - why refusal to treat in reproductive healthcare is not conscientious objection", Woman - Psychosomatic Gynaecology and Obstetrics, 1 (C), pp. 12-23. DOI: https://doi.org/10.1016/j.woman.2014.03.001

Fiala, C., e J. H. Arthur (2017), “There is no defence for 'conscientious objection' in reproductive health care", European Journal of Obstetrics Gynecology and Reproductive Biology, 216, pp. 254-258. DOI: https://doi.org/10.1016/j.ejogrb.2017.07.023

Finer, L., e J. B. Fine (2013), "Abortion law around the world: progress and pushback", American Journal of Public Health, 103 (4), pp. 585-589. DOI: https://doi.org/10.2105/AJPH.2012.301197

Goffman, E. (1963), Stigma, Nova Iorque, Simon \& Schuster.

Green, J., e N. Thorogood (2018), Qualitative Methods for Health Research, Londres, Sage Publications.

Hanschmidt, F., K. Linde, A.a Hilbert, S. G. Riedel-Heller, e A. Kersting (2016), “Abortion stigma: a systematic review", Perspect Sex Reprod Health, 48 (4), pp. 169-177. DOI: $10.1363 / 48 \mathrm{e} 8516$

Harris, L. F., J. Halpern, N. Prata, W. Chavkin, e C. Gerdts (2018), “Conscientious objection to abortion provision: why context matters", Global Public Health, 13 (5), pp. 556-566. DOI: https://doi.org/10.1080/17441692.2016.1229353

Hatzenbuehler, M. L., J. C. Phelan, e B. G. Link (2013), "Stigma as a fundamental cause of population health inequalities", American Journal of Public Health, 103 (5), pp. 813-821. DOI: https://doi.org/10.2105/AJPH.2012.301069

Hill, M. J. (2009), The Public Policy Process, Londres, Longman.

Howlett, M. (2000), “A dialética da opinião pública: efeitos recíprocos da política pública e da opinião pública em sociedades democráticas contemporâneas", Opinião Pública, 6 (2), pp. 167-186. DOI: https://doi.org/10.1590/s0104-62762000000200001

IPPF - International Planned Parenthood Federation (2008), "Access to safe abortion", in Knowledge Creation Diffusion Utilization.

IPPF - International Planned Parenthood Federation (2012), Abortion - Legislation in Europe.

IPPF - International Planned Parenthood Federation (2017), Under-Served and Over-Looked. Disponível em: https://www.ippf.org/sites/default/files/2017-07/IPPF_Underserved_Overlooked.p df (última consulta em maio de 2021).

Jerman, J., L. Frohwirth, M. L. Kavanaugh, e N. Blades (2017), “Barriers to abortion care and their consequences for patients traveling for services: qualitative findings from two states", Perspectives on Sexual and Reproductive Health, 49 (2), pp. 95-102. DOI: https://doi.org/10.1363/psrh.12024

Kaposy, C. (2010), "Improving abortion access in Canada", Health Care Analysis, 18 (1), pp. 17-34. DOI: https://doi.org/10.1007/s10728-008-0101-0

Kero, A., U. Högberg, L. Jacobsson, e A. Lalos (2001), “Legal abortion: a painful necessity", Soc Sci Med, 53 (11), pp. 1481-1490. 
Levels, M., R. Sluiter, e A. Need (2014), “A review of abortion laws in Western-European countries: a cross-national comparison of legal developments between 1960 and 2010", Health Policy, 118 (1), pp. 95-104.

DOI: https://doi.org/10.1016/j.healthpol.2014.06.008

Monteiro, R. (2012), “A descriminalização do aborto em Portugal: Estado, movimentos de mulheres e partidos políticos", Análise Social, 47 (3), pp. 586-605.

Nações Unidas (1976), Pacto Internacional sobre os Direitos Civis e Políticos, 13.258.

Nações Unidas (1979), Convenção para a Eliminação de Todas as Formas de Discriminação contra as Mulheres.

Nações Unidas (1994), Relatório da Conferência Internacional sobre População e Desenvolvimento - Plataforma do Cairo.

Namasivayam, A., D. C. Osuorah, R. Syed, R., e D. Antai (2012), “The role of gender inequities in women's access to reproductive health care: a population-level study of Namibia, Kenya, Nepal, and India", International Journal of Women's Health, 4, pp. 351-364. DOI: https://doi.org/10.2147/IJWH.S32569

Ordem dos Médicos Portugueses (2016), Regulamento de Deontologia Médica.

Ortiz, E. M. (2017), Aborto Legal e Objeção de Consciência. Condições para o Exercício e Compatibilização Desses Direitos, Curitiba, Universidade Federal do Paraná.

Rasch, V., T. Gammeltoft, L. B. Knudsen, C. Tobiassen, A. Ginzel, e L. Kempf (2008), "Induced abortion in Denmark: effect of socio-economic situation and country of birth", European Journal of Public Health, 18 (2), pp. 144-149.

Reis, C. (2017), “Aborto causa estigma entre médicos", Expresso, 30/09/2017.

Rinehart, J. A., e J. Lorber (2002), "Gender inequality: feminist theories and politics", Teaching Sociology, 30 (1), p. 128. DOI: https://doi.org/10.2307/3211533

Robinson, N. (1999), “The use of focus group methodology with selected examples from sexual health research", Journal of Advanced Nursing, 29 (4), pp. 905-913.

Savulescu, J. (2006), “Conscientious objection in medicine”, British Medical Journal, 332 (fevereiro), pp. 2004-2007.

Schuklenk, U. (2018), “Conscientious objection in medicine: accommodation versus professionalism and the public good", British Medical Bulletin, 126 (1), pp. 47-56. DOI: https://doi.org/10.1093/bmb/ldy007

Sociedade Portuguesa de Contraceção (2018), O Aborto Ilegal É Uma das Maiores Causas de Mortalidade Materna no Mundo.

Stifani, B. M., D. Vilar, e L. Vicente (2018), "“'Referendum on Sunday, working group on Monday': a success story of implementing abortion services after legalization in Portugal", International Journal of Gynecology E Obstetrics, 143, pp. 31-37. DOI: https://doi.org/10.1002/ijgo.12675

Tavares, M. (2008), Feminismos em Portugal (1947-2007), Lisboa, Universidade Aberta.

U.S. National Library of Medicine - MedlinePlus (2018), Medical Encyclopedia Miscarriage.

Wicclair, M. R. (2011), “Three approaches to conscientious objection in health care: conscience absolutism, the incompatibility thesis, and compromise", em Mark Wicclair, Conscientious Objection in Health Care. An Ethical Analysis, Cambridge, Cambridge University Press, pp. 32-86.

DOI: https://doi.org/10.1017/CBO9780511973727.003 
Wilkinson, Richard, e K. Pickett (2010), O Espírito da Igualdade. Por Que Razão Sociedades Igualitárias Funcionam Quase Sempre Melhor, Lisboa, Presença.

Yishai, Y. (1993), "Public ideas and public policy: abortion politics in four democracies", Comparative Politics, 25 (2), pp. 207-228.

Zahariadis, N. (2007), “The multiple streams framework”, em P. A. Sabatier (org.), Theories of the Policy Process, Boulder, CO, Westview Press, pp. 65-92 (2. edição).

Zampas, C., e X. Andión-Ibañez (2012), “Conscientious objection to sexual and reproductive health services: international human rights standards and European law and practice", European Journal of Health Law, 19 (3), pp. 231-256.

DOI: https://doi.org/10.3868/s050-004-015-0003-8

\section{Fontes}

Constituição da República Portuguesa (1976), Diário da República n.․ 86/1976, série I de 10/04/1976, Assembleia da República Portuguesa.

Iniciativa Legislativa de Cidadãos (2015), Lei de Apoio à Maternidade e Paternidade do Direito a Nascer.

Lei n. ${ }^{\circ}$ 16/2007, de 17 de abril - Exclusão da ilicitude nos casos de interrupção voluntária da gravidez, Diário da República n.ํ75/2007, série I de 17/04/2007. Disponível em: https://dre.pt/web/guest/pesquisa/-/search/519464/details/normal?l=1 (última consulta em maio de 2021).

Lei n.․ 6/84, de 11 de maio - Exclusão de ilicitude em alguns casos de interrupção voluntária de gravidez, Diário da República, n.․109-I série (1984). Disponível em: https://dre.pt/pesquisa/-/search/385266/details/normal?jp=true/en (última consulta em maio de 2021).

Programa do XVII Governo Constitucional (2005). Disponível em: https://www.historico.portugal.gov.pt/pt/o-governo/arquivo-historico/governos-co nstitucionais/gc17/programa-do-governo/programa-do-xvii-governo-constituciona l.aspx (última consulta em maio de 2021).

Miguel Areosa Feio. Psicólogo clínico e técnico superior de Políticas Públicas, Instituto Superior de Psicologia Aplicada/Iscte - Instituto Universitário de Lisboa. E-mail: miguelareosafeio@gmail.com

ORCID : https://orcid.org/0000-0002-6895-1983

Receção: 9 de janeiro de 2020 Aprovação: 11 de setembro de 2020 